\title{
Long non-coding RNAs towards precision medicine in gastric cancer: early diagnosis, treatment, and drug resistance
}

\author{
Li Yuan $^{1 \dagger}$, Zhi-Yuan Xu ${ }^{2 \dagger}$, Shan-Ming Ruan', Shaowei Mo ${ }^{1}$, Jiang-Jiang Qin ${ }^{2,3^{*}}$ (D) and Xiang-Dong Cheng ${ }^{2 *}$
}

\begin{abstract}
Gastric cancer is a deadly disease and remains the third leading cause of cancer-related death worldwide. The 5year overall survival rate of patients with early-stage localized gastric cancer is more than $60 \%$, whereas that of patients with distant metastasis is less than $5 \%$. Surgical resection is the best option for early-stage gastric cancer, while chemotherapy is mainly used in the middle and advanced stages of this disease, despite the frequently reported treatment failure due to chemotherapy resistance. Therefore, there is an unmet medical need for identifying new biomarkers for the early diagnosis and proper management of patients, to achieve the best response to treatment. Long non-coding RNAs (IncRNAs) in body fluids have attracted widespread attention as biomarkers for early screening, diagnosis, treatment, prognosis, and responses to drugs due to the high specificity and sensitivity. In the present review, we focus on the clinical potential of IncRNAs as biomarkers in liquid biopsies in the diagnosis and prognosis of gastric cancer. We also comprehensively discuss the roles of IncRNAs and their molecular mechanisms in gastric cancer chemoresistance as well as their potential as therapeutic targets for gastric cancer precision medicine.
\end{abstract}

Keywords: LncRNA, Gastric cancer, Precision medicine, Early diagnosis, Cancer treatment, Chemoresistance

\section{Background}

Gastric cancer is one of the most common malignancies worldwide, with more than one million new cases every year, and remains the third leading cause of cancerrelated deaths $[1,2]$. The clinical stage at the time of diagnosis directly determines the prognosis of patients with this disease. The patients with localized, early-stage gastric cancer usually have a high 5-year overall survival (OS) rate $(>60 \%)$, whereas the 5 -year OS rates for gastric cancer patients with local and distant metastasis

\footnotetext{
* Correspondence: jain@zcmu.edu.cn; zylysjtu@hotmail.com; chengxd516@126.com

${ }^{+} \mathrm{Li}$ Yuan and Zhi-Yuan Xu contributed equally to this work.

${ }^{2}$ Institute of Cancer and Basic Medicine, Chinese Academy of Sciences, Cancer Hospital of the University of Chinese Academy of Sciences, Zhejiang Cancer Hospital, Banshan Road 1\#, Gongshu District, Hangzhou 310022, China

Full list of author information is available at the end of the article
}

dramatically decrease to 30 and $5 \%$, respectively [2]. Unfortunately, due to the occult and atypical nature of early clinical symptoms of gastric cancer, more than $60 \%$ of patients have local or distant metastases at the time of diagnosis [2]. For patients with early gastric cancer, surgical resection is the best treatment option; for patients who cannot undergo surgical resection or patients with advanced metastases, chemotherapy is the most important treatment [3, 4]. However, poor or even no response to chemotherapy is often observed in gastric cancer patients because of the intrinsic or acquired resistance, which becomes the most common cause of treatment failure [5]. Therefore, the low rate of early diagnosis and chemotherapy resistance constitute the main contributions to the poor prognosis of gastric cancer.

To date, the biomarkers commonly used in early screening for gastric cancer include carcinoembryonic 
antigen (CEA), alpha-fetoprotein (AFP), carbohydrate antigen 19-9 (CA19-9), CA72-4, CA125, etc. [6, 7]. However, the sensitivities and positive rates of these biomarkers are poor; their sensitivities in the diagnosis of gastric cancer are from 4.7 to $33.3 \%$, and the positive rates of CEA, CA199, and CA724 only range from 21.1 to $30 \%$ [7-9]. The diagnosis of gastric cancer still depends on upper gastrointestinal endoscopy, but its clinical application is limited because of the invasiveness and high cost [10]. Therefore, there is an urgent need for minimal-invasive or non-invasive detection approaches, as well as highly specific biomarkers, to improve gastric cancer early diagnosis and survival outcomes.

Long non-coding RNAs (lncRNAs) have attracted increasing attention as cancer biomarkers for early screening, diagnosis, prognosis, and responses to drug treatment [11-13]. A recent study has shown that the expression of lncRNA MNX1-AS1 (MNX1 antisense RNA 1) is significantly increased in gastric cancer tissues and associated with the poor prognosis of gastric cancer patients [14]. LncRNA SNHG11 (small nucleolar RNA host gene 11) has been reported as a potential biomarker for early detection of colon cancer and a new therapeutic target of this disease [15]. A stroma-related lncRNA panel has been found to predict recurrence and adjuvant chemotherapy benefit in patients with earlystage colon cancer [16]. LncRNAs are involved in the acquired resistance to chemotherapy $[17,18]$, and targeting lncRNA can reverse drug resistance and enhance the sensitivity of cancer cells to chemotherapy [19]. Given the importance of IncRNAs in cancer, a better understanding of their roles in the early diagnosis, treatment, prognosis, and drug resistance of gastric cancer may provide new insights for precise treatment and individualized management of patients with this disease.

The regulation of lncRNA expression and the roles of lncRNAs in gastric cancer progression and metastasis have been extensively discussed in several recent reviews [20-24]. In the present review, we focus on the clinical evidence of lncRNAs as biomarkers in liquid biopsies in the early diagnosis and prognosis of gastric cancer. We also comprehensively discuss the roles of lncRNAs and their molecular mechanisms in gastric cancer chemoresistance, as well as their potential as therapeutic targets for gastric cancer precise medicine.

\section{An overview of IncRNAs}

The Encyclopedia of DNA Elements (ENCODE) project has revealed that only about $1.2 \%$ of human transcripts (RNAs) encode proteins and more than $98 \%$ of human transcripts are non-protein-coding RNAs (ncRNAs), such as lncRNAs, circular RNAs (circRNAs), microRNAs (miRNAs), and small nucleolar RNAs (snoRNAs)
[25]. LncRNAs are the transcripts of more than $200 \mathrm{nu}$ cleotides, accounting for 80 to $90 \%$ of all ncRNAs and are characterized by low expression levels, poor interspecies conservation, and high expression coefficient of variance $[26,27]$.

According to their genomic localization and evolutionary lineage, lncRNAs can be divided into intergenic lncRNAs, intronic lncRNAs, exonic lncRNAs, sense lncRNAs, and antisense lncRNAs. Intergenic lncRNAs (also called lincRNAs) are transcribed from genomic regions between coding genes, while intronic lncRNAs overlap entirely with introns of protein-coding genes and exonic lncRNAs overlap entirely or partially with exons of protein-coding genes $[28,29]$. The transcriptional orientation of IncRNAs can be in sense or antisense when compared with the transcriptional orientation of the protein-coding genes [30]. Besides, lncRNAs can be classified into nuclear lncRNAs and cytoplasmic lncRNAs based on the subcellular localization, which is critical for their functions. Most lncRNAs are located in the nucleus and only about $15 \%$ are in the cytoplasm [31]. Nuclear lncRNAs mainly regulate the transcription or mRNA processing, e.g. lncRNA XIST ( $\mathrm{X}$ inactive specific transcript), MALAT1 (metastasis associated lung adenocarcinoma transcript 1), and NEAT1 (nuclear paraspeckle assembly transcript 1) functioning as transcription regulators [32-34]. Cytoplasmic lncRNAs are more often involved in posttranscriptional regulation, such as playing the role of miRNA sponges. $\mathrm{Du}$ et al. have demonstrated that cytoplasmic localization is an important factor in determining the sponge efficacy of lncRNA TUG1 (taurine up-regulated 1) [35]. Cytoplasmic IncRNA PVT1 (plasmacytoma variant translocation 1) has been found to act as a competitive endogenous RNA (ceRNA) against miR-214-3p and promote the progression of colon cancer [36].

LncRNAs were initially considered as "junk" or "genomic dark matter" without function. With the deepening of research in recent years, lncRNAs have been found to participate widely in various physiological and pathological processes of organisms. In the human body, lncRNAs not only regulate the physiological processes such as cell proliferation, differentiation, and apoptosis but also participate in regulating various pathological processes of the body, such as cancer, cardiovascular diseases, autoimmune diseases, diabetes, and more [37-40]. The specific function of lncRNAs is to regulate gene expression at the pre-transcriptional, transcriptional, and post-transcriptional levels. At the pre-transcriptional level, lncRNA regulates gene expression by gene modification, histone modification, and chromatin remodeling, without changing the DNA sequences of the organisms [41, 42]. During transcription, lncRNA interacts with 
transcription factors to regulate gene transcription [43]. At the post-transcriptional level, lncRNA acts as a precursor of some miRNAs to regulate gene expression, or as a ceRNA to regulate the translation of the corresponding mRNA [44]. However, due to the large number of lncRNAs, the functions of most lncRNAs are still unclear and require further comprehensive research.

\section{LncRNAs as liquid biopsy biomarkers of gastric cancer}

The development of liquid biopsies has opened a new era for precision medical treatment of human cancer. Because of their minimal-invasive or non-invasive characteristics and high public acceptance, liquid biopsies can be conducted more frequently for early screening, diagnosis, and prognosis of cancer. Besides, liquid biopsies can be collected at specific time intervals to monitor responses to treatment, drug resistance, recurrence, and metastasis of cancer. Added benefits are that, unlike tissue biopsies obtained from only one tumor area, liquid biopsies may better reflect the genetic characteristics of all tumor subclones in patients [45]. LncRNAs are widely distributed in peripheral plasma/serum, saliva, gastric juice, urine, semen, and other liquids and play important roles in various aspects of human physiological and pathological processes [46-50]. Based on the aforementioned benefits, a comprehensive understanding of the current research status of lncRNAs is critical for the further development of them as cancer biomarkers in liquid biopsies.

Accumulating evidence suggests the usefulness of IncRNAs as liquid biopsy biomarkers for human cancer. LncRNAs in peripheral blood plasma/serum have been demonstrated as biomarkers for various types of human cancer, such as lung, breast, and colon cancer [51-53]. LncRNAs in saliva have been mainly used as biomarkers for head and neck cancer, such as oral, pharyngeal, and laryngeal cancer $[54,55]$. LncRNAs in gastric juice and urine have also been reported as biomarkers of gastric cancer and urinary system cancer, respectively [49]. Of note, the urinary level of lncRNA PCA3 (prostate cancer associated 3) has been used as a biomarker for the diagnosis of prostate cancer in clinical applications $[56,57]$. Although there is no report on lncRNAs in semen, recent studies have shown that miRNAs in semen may be used as biomarkers for prostate cancer [58]. To date, almost all attention has been paid to the lncRNAs in plasma/serum and gastric juice but not in other liquid biopsies as biomarkers of gastric cancer, which has been comprehensively discussed in this section.

\section{LncRNAs in plasma/serum as diagnostic and prognostic} biomarkers of gastric cancer

The development of a disease often leads to changes in the plasma/serum composition, which can be detected to reflect the status of the disease [59]. LncRNAs, which are freely circulating in the plasma/serum or packaged in exosomes, have all of the characteristics of ideal biomarkers because they are stable over long periods at room temperature, during repeated freeze-thaw cycles, or at different $\mathrm{pH}$ values [60]. More importantly, the plasma/serum levels of lncRNAs are mostly the same as those in the primary tumor tissues, thus precisely reflecting the characteristics of the tumors [61, 62]. In addition, the collection of plasma/serum samples at different time points is relatively convenient for monitoring the progress of the disease [63-66].

\section{LncRNAs in plasma/serum as diagnostic biomarkers of gastric cancer}

A large number of circulating lncRNAs have been reported as biomarkers for the diagnosis of gastric cancer (as summarized in Table 1), which have obvious advantages over the diagnostic biomarkers in clinical applications. Xian et al. have found that lncRNA HULC (hepatocellular carcinoma upregulated long noncoding RNA) and ZNFX1-AS1 (ZNFX1 antisense RNA 1) can distinguish gastric cancer patients from healthy controls and have proposed them as biomarkers for diagnosing gastric cancer [77]. The receiver operator characteristic curve (ROC) analysis has shown that the area under curve (AUC) values for HULC and ZNFX1-AS1 are 0.65 and 0.85 , respectively, which are higher than those of traditional serum biomarkers, including CEA (0.62), CA19-9 (0.56), CY211 (0.59), and neuron-specific enolase (NSE, 0.56) [77]. Jin et al. have further confirmed that HULC is more sensitive and specific than CEA and CA724 as a diagnostic marker of gastric cancer [82]. Yang et al. have found that the AUC values of lncRNA PANDAR (promoter of CDKN1A antisense DNA damage activated RNA), FOXD2-AS1 (FOXD2 adjacent opposite strand RNA 1), and SMARCC2 (SWI/SNF related, matrix associated, actin dependent regulator of chromatin subfamily c member 2) as diagnostic biomarkers of gastric cancer are $0.77,0.7$, and 0.75 , respectively, which are similar to the AUC value of combined CEA, AFP, CA125, CA153, and CA199 [97]. Feng et al. have also demonstrated that IncRNA B3GALT5-AS1 (B3GALT5 antisense RNA 1) is better than CEA and CA19-9 as a diagnostic biomarker of gastric cancer [87]. Zhou et al. have recently reported that lncRNA C5orf66AS1 (C5orf66 antisense RNA 1) can be utilized for the diagnosis of gastric cancer with the AUC value of 0.688 [67]. More importantly, IncRNA C5orf66-AS1 has further been shown to predict early gastric cancer with the AUC value of 0.789 [67].

Circulating lncRNAs have better biomarker values when combined, e.g. combining IncRNA PANDAR, FOXD2-AS1, and SMARCC2 increases the AUC value 


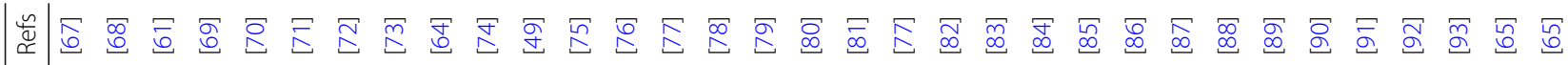

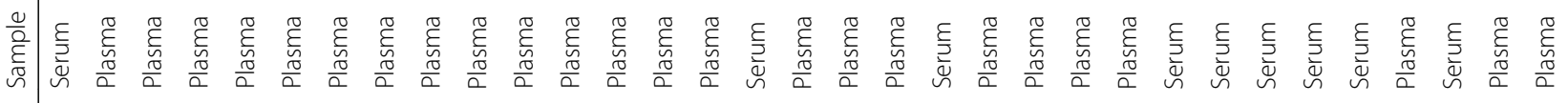

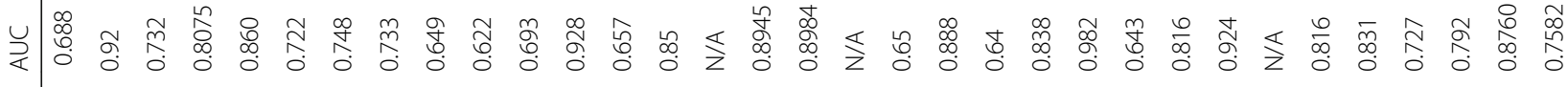

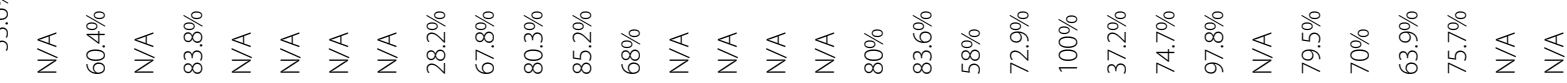

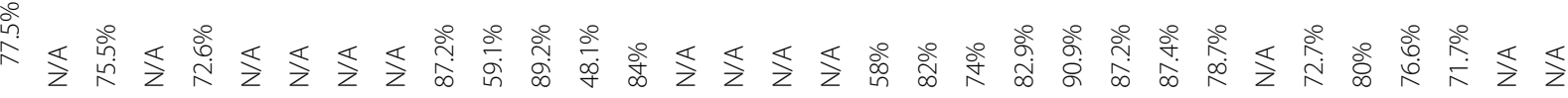

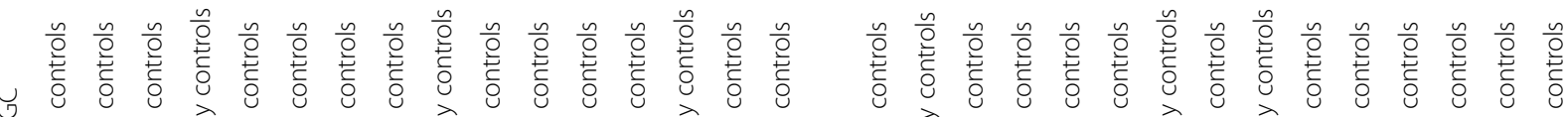

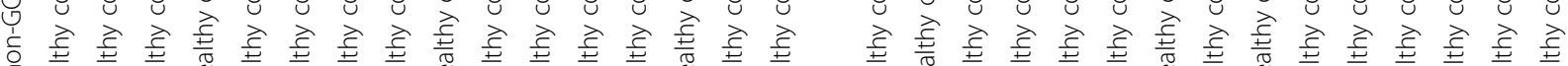

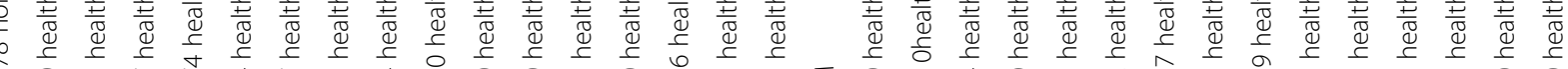

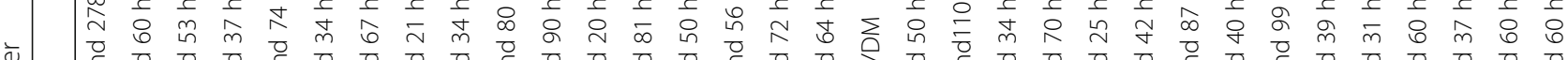

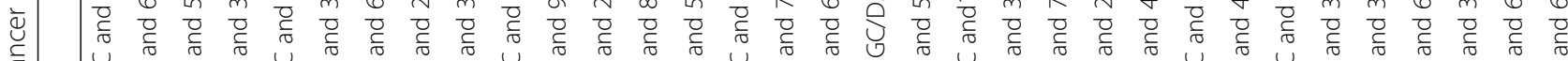

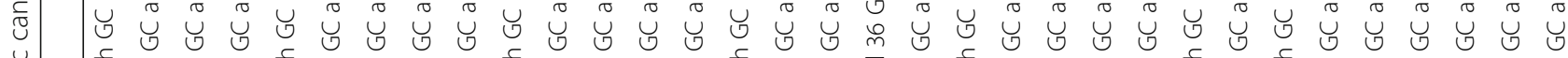

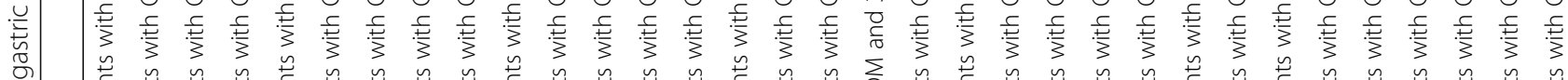

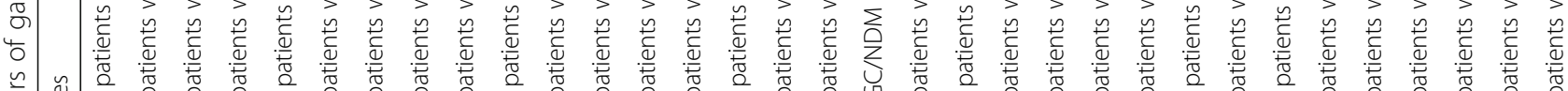

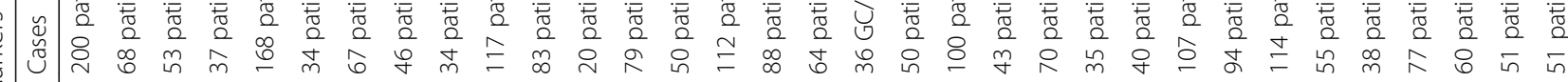

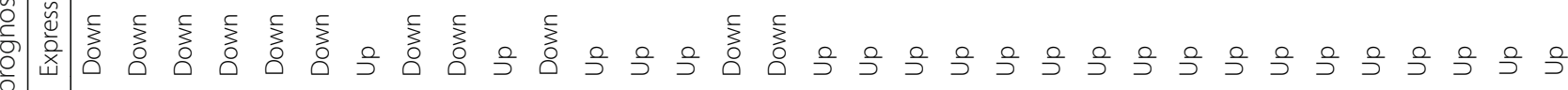

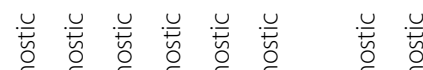

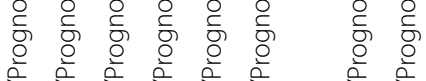

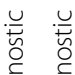

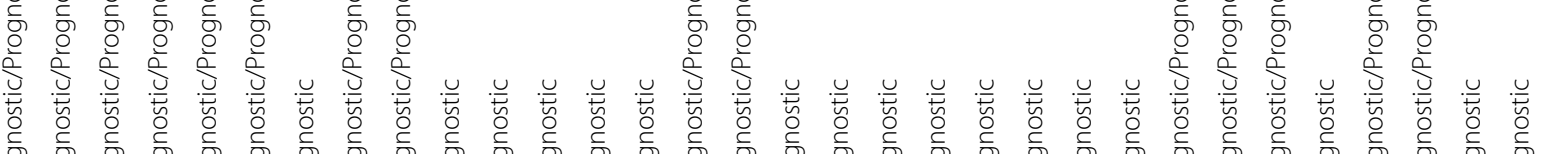

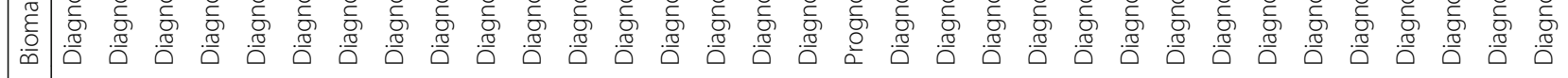

勇

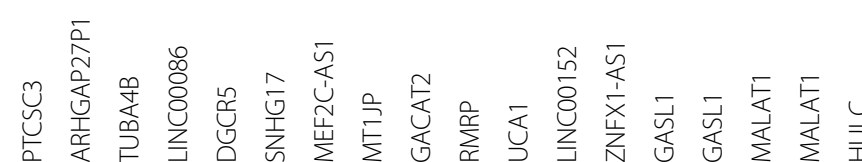

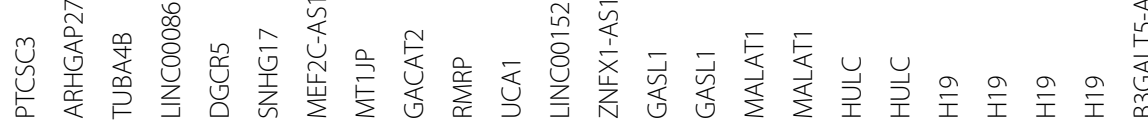

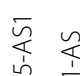




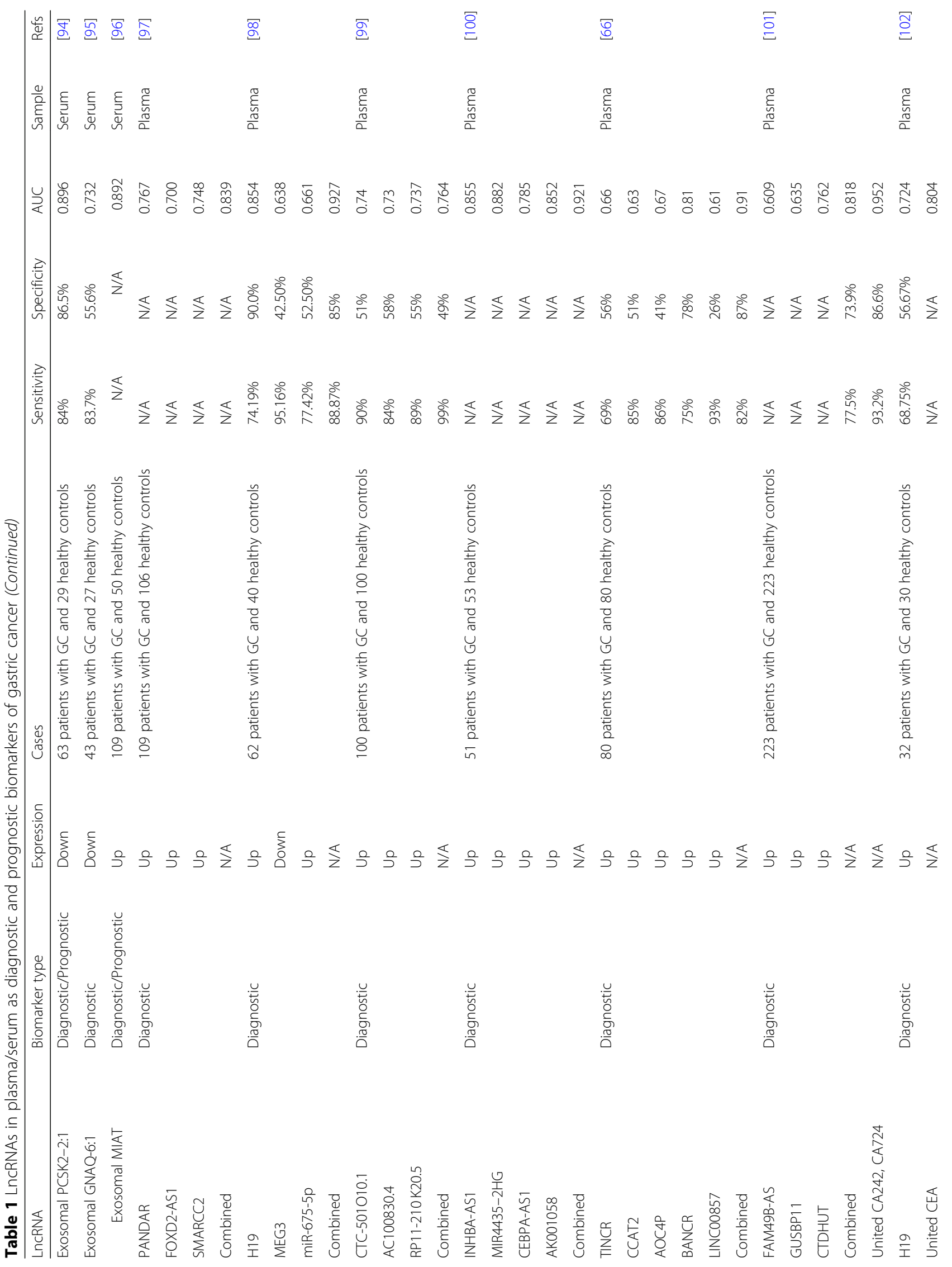




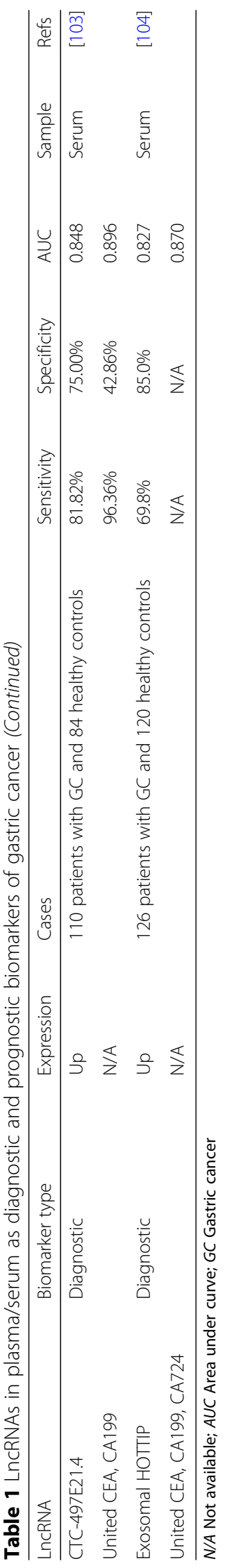


to 0.84 [97]. The combination of lncRNA CTC501O10.1, AC100830.4, and RP11-210 K20.5 has been found to improve the sensitivity of the diagnosis to $99 \%$ [99]. The combination of IncRNA INHBA-AS1 (INHBA antisense RNA 1), MIR4435-2HG (MIR4435-2 host gene), CEBPA-AS1 (CEBPA divergent transcript), and AK001058 has increased the AUC value to 0.92 [100]. Also, the combination of lncRNA TINCR (terminal differentiation-induced ncRNA), CCAT2 (colon cancer associated transcript 2), AOC4P (amine oxidase copper containing 4, pseudogene), BANCR (BRAF-activated non-protein coding RNA), and LINC00857 has increased the AUC value to 0.91 , the sensitivity to $82 \%$, and the specificity to $87 \%$ [66]. Meanwhile, combining lncRNAs and miRNAs have also improved their diagnostic efficiency, e.g. the AUC value of IncRNA H19 (H19 imprinted maternally expressed transcript) and MEG3 (maternally expressed 3) combined with miR-675-5p is 0.93 while the specificity and sensitivity are 88.9 and $85 \%$, respectively [98]. However, the sensitivities of H19, MEG3, and miR-675-5p are 74.19, 95.16, and 77.42\%, respectively, their respective specificities are 90.0, 42.50, and $52.50 \%$, and their AUC values range from 0.638 to 0.854 [98]. Moreover, IncRNAs combined with traditional serum tumor markers have improved the diagnostic efficiency, e.g. IncRNA CTC-497E21.4 combined with CEA and CA199 has increased the AUC value to 0.9 [103]. Using the lncRNA FAM49B-AS (FAM49B antisense RNA), GUSBP11 (GUSB pseudogene 11), and CTDHUT (CTD highly upregulated transcript) combined with A242 and CA724, the AUC value, sensitivity, and specificity have been increased to $0.95,93.2$, and $86.6 \%$, respectively [101].

\section{LncRNAs in plasma/serum as prognostic biomarkers of gastric cancer}

Tumor size, stage, depth of invasion, lymph node metastasis, distant metastasis, and pathological type are the relevant factors for the prognosis of cancer patients [105]. Circulating lncRNAs have been associated with these prognosis-related factors and have been demonstrated as prognostic biomarkers of gastric cancer (as summarized in Table 1). It has been found that the expression levels of lncRNA GASL1 (growth arrest associated IncRNA 1), PTCSC3 (papillary thyroid carcinoma susceptibility candidate 3 ), and MALAT1 are significantly correlated with tumor size, TNM (tumor, node, metastasis) stage, and distant metastasis of gastric cancer, respectively $[68,79,80]$. The expression levels of lncRNA SNHG6, ARHGAP27P1 (Rho GTPase activating protein 27 pseudogene 1), DANCR (differentiation antagonizing non-protein coding RNA), DGCR5 (DiGeorge syndrome critical region gene 5), MT1JP (metallothionein $1 \mathrm{~J}$, pseudogene), SNHG17, and ZFAS1 (ZNFX1 antisense RNA 1) are closely related to the TNM stage, tumor invasion depth, and lymph node metastasis of gastric cancer [61, 64, 71, 72, 89, 90, 92]. It has also been reported that IncRNA HOXA11-AS (HOXA11 antisense RNA) and TUBA4B (tubulin alpha 4b) are tightly correlated with the tumor size, TNM stage, and lymph node metastasis of gastric cancer [69, 88]. Importantly, the Kaplan-Meier survival curve analysis has indicated that the patients with low expression of HOXA11-AS have a better survival rate, whereas the patients with low expression of TUBA4B have a shorter survival time [69, 88]. Tan et al. have demonstrated a significant correlation between the expression level of lncRNA GACAT2 (gastric cancer associated transcript 2) and the lymph node metastasis, distant metastasis, and perineural invasion of gastric cancer [74]. In addition, Ji et al. have shown that LINC00086 expression level is significantly associated with tumor size, lymph node metastasis, TNM stage, and the levels of CEA and CA19-9, while the gastric cancer patients with low expression of LINC00086 have low survival rates [70].

\section{Exosomal IncRNAs in plasma/serum as diagnostic and prognostic biomarkers of gastric cancer}

In the blood, long RNAs may be packaged into extracellular vesicles, which makes them more stable in plasma/ serum. According to their diameters, the extracellular vesicles are classified into apoptotic bodies $(50-5000$ $\mathrm{nm})$, microvesicles $(50-1000 \mathrm{~nm})$, and exosomes (30$100 \mathrm{~nm}$ ) [106]. Apoptotic bodies are produced by cells undergoing programmed cell death, microvesicles are vesicles directly released from cell membranes, and exosomes are intracellular in origin $[107,108]$. Among these types of vesicles, exosomes are the most abundant reservoir of lncRNAs [106]. Due to their intracellular origin and high quantities of long RNAs, circulating exosomal lncRNAs have been proposed as promising biomarkers for gastric cancer [109].

Compared with traditional diagnostic biomarkers (CEA, CA724, and CA199), circulating exosomal lncRNA PCSK2-2:1 (proprotein convertase subtilisin/ kexin type 2-2:1) and GNAQ-6:1 (G protein subunit alpha q-6:1) have been reported as better biomarkers for distinguishing gastric cancer patients from healthy people. The AUCs (0.9 and 0.74, respectively), sensitivities ( 84 and $83.7 \%$, respectively), and specificities ( 86.5 and 55.6\%, respectively) of PCSK2-2:1 and GNAQ-6:1 are significantly better than the best traditional diagnostic biomarker CA724, which only has an AUC value of 0.57 , a sensitivity of $56 \%$, and a specificity of $65.5 \%$ [ 94 , 95]. It has also been shown that the exosomal PCSK2-2: 1 level is significantly related to the tumor size, TNM stage, and venous infiltration and may be developed as a prognostic biomarker of gastric cancer [94]. Lin et al. 
have found that the expression levels of exosomal lncRNA UEGC1 (ENST00000568893) and UEGC2 (ENST00000378432.1) are increased in patients with gastric cancer [65]. The stability tests have shown that almost all plasma UEGC1 is encapsulated by exosomes and has a higher AUC value while UEGC2 is only partially encapsulated by exosomes, suggesting that UEGC1 is more suitable to be developed as a diagnostic biomarker for early gastric cancer [65]. Xu et al. have shown that the serum level of exosomal lncRNA MIAT (myocardial infarction associated transcript) is significantly increased in gastric cancer patients, which is associated with worse clinical variables and shorter survival [96]. Moreover, it has been found that the serum exosomal MIAT is down-regulated in patients after treatment but markedly up-regulated in patients suffering recurrence [96]. Furthermore, exosomal lncRNAs combined with serum tumor markers have shown improved diagnostic accuracy, e.g., exosomal lncRNA HOTTIP (HOXA distal transcript antisense RNA) combined with CEA, CA199, and CA724 have been found to increase the AUC value from 0.83 to 0.87 [104].

Taken together, IncRNAs in plasma/serum have shown great potential as biomarkers for the diagnosis and prognosis of gastric cancer. Importantly, the combinations, including but not limited to multiple lncRNAs combinations, lncRNA and miRNA combinations, and lncRNA and serum tumor marker combinations usually have better values as diagnostic biomarkers compared to an individual lncRNA. The exosomal lncRNAs in plasma/serum have also shown an advantage as biomarkers due to their high stability; however, further verification studies are needed. Moreover, controversial results have been obtained for the same lncRNA in gastric cancer. LncRNA H19 has been demonstrated as a diagnostic biomarker of gastric cancer with a large range of AUC values (0.6-0.98) in recent studies, which may be correlated with the individual differences [83-86]. Further investigations with larger sample size are warranted for improving accuracy and precision. The specific source and molecular mechanisms of lncRNAs in plasma/serum are yet to be determined.

\section{LncRNAs in gastric juice as diagnostic and prognostic biomarkers of gastric cancer}

Gastric juice is directly secreted by the gastric mucosa and can sensitively reflect the pathological state of the stomach, making it an ideal sample for studying gastric cancer [110]. Recent studies have shown that lncRNAs in gastric juice are specific and their expression levels may be inconsistent with those in tissue and plasma. Fei et al. have found that the expression level of LINC00982 is significantly decreased in tumor tissues but increased in gastric juice from patients with gastric cancer [111].
Similar results have been obtained for lncRNA RMRP (RNA component of mitochondrial RNA processing endoribonuclease) and AA174084 by Shao et al. [49, 112]. It has been speculated that some lncRNAs may be secreted actively by gastric cancer cells during the disease process or partly by exosomes or other pathways [112].

To date, several IncRNAs, including RMRP, AA174084, PVT1, H19, LINC00982, ABHD11-AS1 (ABHD11 antisense RNA 1), UCA1 (urothelial cancer associated 1), and LINC00152 have been identified from gastric juice and demonstrated as biomarkers for gastric cancer. The sensitivities, specificities, and AUC values of these newly characterized diagnostic biomarkers of gastric cancer range from 41 to $56.4 \%, 75.4$ to $93.4 \%$, and 0.65 to 0.85 , respectively. Furthermore, the expression level of AA174084 in gastric juice has been correlated with tumor size, tumor stage, Lauren type, and CEA level in the gastric juice, and a higher AA174084 level in gastric juice indicates a poorer prognosis of gastric cancer patients [112]. The expression level of ABHD11-AS1 in gastric juice has also been associated with the tumor size, tumor stage, and CEA level in the blood, while the high level of ABHD11-AS1 suggests an increased risk of gastric cancer recurrence [113]. Therefore, AA174084 and ABHD11-AS1 can be used for both the diagnosis and prognosis of gastric cancer. In addition, the combination of gastric juice ABHD11-AS1, serum CEA, and gastric juice CEA can improve the diagnostic accuracy of early gastric cancer [113].

In summary, due to the high specificity and reliability, gastric juice lncRNAs can be used as biomarkers for the diagnosis and prognosis of gastric cancer. However, an individual gastric juice lncRNA always has high specificity but insufficient sensitivity as a biomarker. More combination studies, such as the combination of multiple gastric juice lncRNAs, the combination of gastric juice lncRNAs with plasma lncRNAs, and the combination of gastric juice lncRNAs with serum tumor markers may be carried out to increase the sensitivity. Also, further investigations are needed to explore the specific source and molecular mechanisms of gastric juice lncRNAs.

\section{LncRNA-mediated regulation of chemoresistance in gastric cancer}

Chemotherapy is the main treatment option for patients with advanced gastric cancer, while drug resistance is the major cause of gastric cancer treatment failure. The mechanisms of cancer chemoresistance include, but not limited to, drug degradation, amplification and overexpression of oncogenes, anti-apoptosis, immune escape, epithelial-mesenchymal transition (EMT), cancer stemness, autophagy, epigenetic modifications, and up- 
regulation of multidrug resistance (MDR)-related genes [114-119]. Recent studies have shown that lncRNAs are widely involved in regulating various mechanisms of cancer chemoresistance [120]. LncRNAs have been found to regulate drug resistance by acting as a ceRNA or directly binding to mRNAs or proteins and modulating their expression and/or functions. In this section, we provide a summary of the molecular mechanisms for lncRNAs-mediated gastric cancer chemoresistance (as summarized in Table 2).

\section{LncRNA-mediated cell apoptosis}

Many anticancer drugs have been found to induce apoptosis and apoptosis-related signaling networks [159, 160]. However, the dysregulation of apoptosis often leads to drug resistance and treatment failure [161]. There are two major pathways of apoptosis, i.e. the extrinsic and intrinsic pathways (mitochondrial pathway) $[162,163]$. The extrinsic pathway is initiated by the attachment of death receptors with their death initiating ligands, such as Fas cell surface death receptor (FAS) binding to FAS ligand (FASL), tumor necrosis factor receptor 1 (TNFR1) binding to tumor necrosis factor alpha (TNF $\alpha$ ), and TRAIL cell surface receptors 1 and 2 (TRAILR1/2) binding to TNFrelated apoptosis-inducing ligand (TRAIL) [163]. Consequently, an adaptor molecule, FAS-associated death domain protein (FADD) couples the death receptors, which leads to the activation of caspase- 8 and caspase-10 [163]. Either activated caspase-8 or caspase-10 can directly cleave and activate caspase- 3 , caspase-6, or caspase-7, thereby promoting apoptosis. Alternatively, irreparable genetic damage, hypoxia, and other internal stimulation can activate apoptosis through the internal mitochondrial pathway. Subsequently, BH3-only protein members, BAX (BCL-2 associated $\mathrm{X}$, apoptosis regulator) and BAK (BCL-2 antagonist/killer), which belong to the B-cell lymphoma-2 (BCL-2) family, can neutralize the antiapoptotic proteins BCL-2 and BCL-xL (B-cell lymphoma-extra large) [162, 163]. Simultaneously, activation of BAX/BAK can increase the permeability of the mitochondrial outer membrane (MOM) and release different apoptosis mediators, such as cytochrome c, which can activate caspase-9. In turn, caspase- 9 cleaves and activates caspase-3, caspase-6, and caspase-7, thus triggering apoptosis [161, 164]. Moreover, PI3K (phosphatidylinositol 3-kinase)/AKT (serine/threonine protein kinase B), Hippo, Wnt/ $\beta$-catenin, and HIF- $1 \alpha$ (hypoxia-inducible factor- $1 \alpha$ ) signaling pathways are involved in regulating apoptosis. Recent studies have shown that lncRNAs can regulate gastric cancer chemoresistance by modulating these apoptosis-related signaling pathways (Fig. 1).

\section{Extrinsic apoptosis pathway}

The abnormal expression of caspase- 8 and caspase-3 leads to the inhibition of apoptosis and chemotherapy resistance [165]. Hang et al. have reported that the overexpression of lncRNA AK022798 down-regulates the expression of caspase- 8 and caspase- 3 and inhibits the extrinsic apoptosis pathway, leading to cisplatin (DDP) resistance in gastric cancer cells, while interference with AK022798 increases the expression levels of caspase-8 and caspase- 3 and promotes apoptosis, reversing chemotherapy resistance in vitro [124]. Fang et al. have revealed that lncRNA UCA1 functions as a sponge of miR-27b to down-regulate caspase- 3 expression and inhibit extrinsic apoptosis pathway, thereby inducing the resistance of gastric cancer cells to DDP, adriamycin (ADR), and 5-fluorouracil (5-FU). It has further been shown that silencing UCA1 increases the expression level of caspase-3, thus promoting apoptosis and reversing MDR in gastric cancer cells in vitro [145, 146].

\section{Intrinsic apoptosis pathway (mitochondrial pathway)}

The pro-apoptotic proteins (BAX, BAK) and antiapoptotic proteins (BCL-2, BCL-xL) maintain a dynamic balance in regulating the mitochondrial apoptosis pathway, while the broken balance often causes cancer progression and chemoresistance $[166,167]$. Li et al. have shown that lncRNA SNHG5 expression is remarkably higher in DDP-resistant gastric cancer patients and cells [150]. Further mechanism study has revealed that SNHG5 down-regulates BAX expression and upregulates BCL-2 expression, thereby inhibiting apoptosis and promoting DDP resistance of gastric cancer cells. Similar results have been obtained for IncRNA GHET1 (gastric carcinoma proliferation enhancing transcript 1) by Zhang et al [143]. Moreover, interfering with GHET1 expression causes an increase in BAX level and a decrease in BCL-2 level, thus enhancing the sensitivity of BGC823 and SGC7901 cells to chemotherapy [143]. Du et al. have reported that IncRNA PVT1 inhibits apoptosis and enhances 5-FU resistance of gastric cancer by activating BCL-2 [147]. A Kaplan-Meier analysis has shown that therapy without 5 -FU significantly improves the first progression survival and OS of gastric cancer patients with high PVT1 expression, while these patients do not experience survival-related benefits from 5-FUbased chemotherapy [147]. Zhang et al have shown that lncRNA FAM84B-AS (FAM84B antisense RNA) increases the expression levels of BCL-2 and BCL-xL and decreases the expression levels of caspase-9, caspase-3, and caspase-7, consequently inhibiting apoptosis and causing gastric cancer cell resistance to DDP; however, silencing FAM84B-AS enhances gastric cancer cell sensitivity to DDP in vitro and in vivo [152]. 


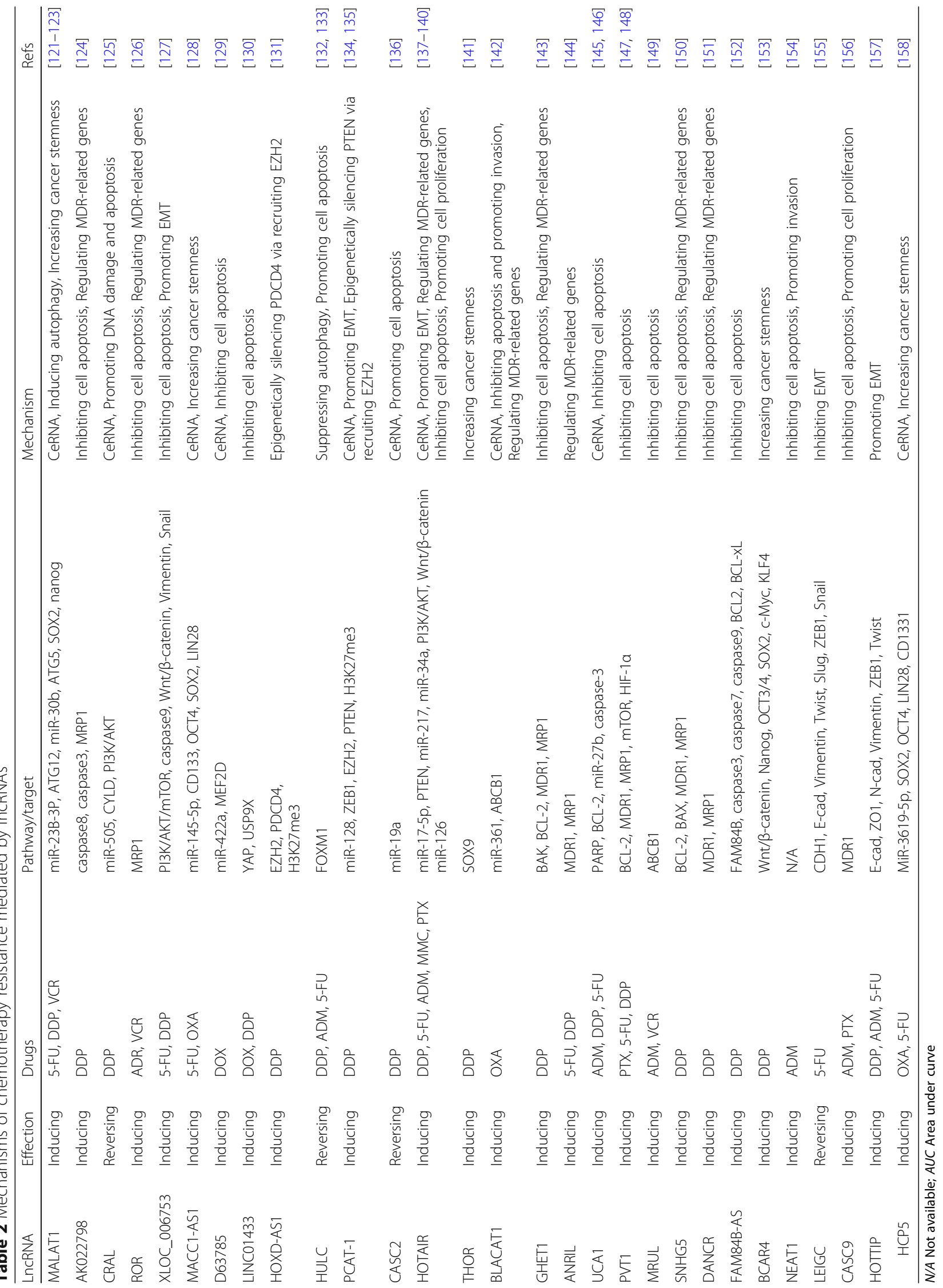




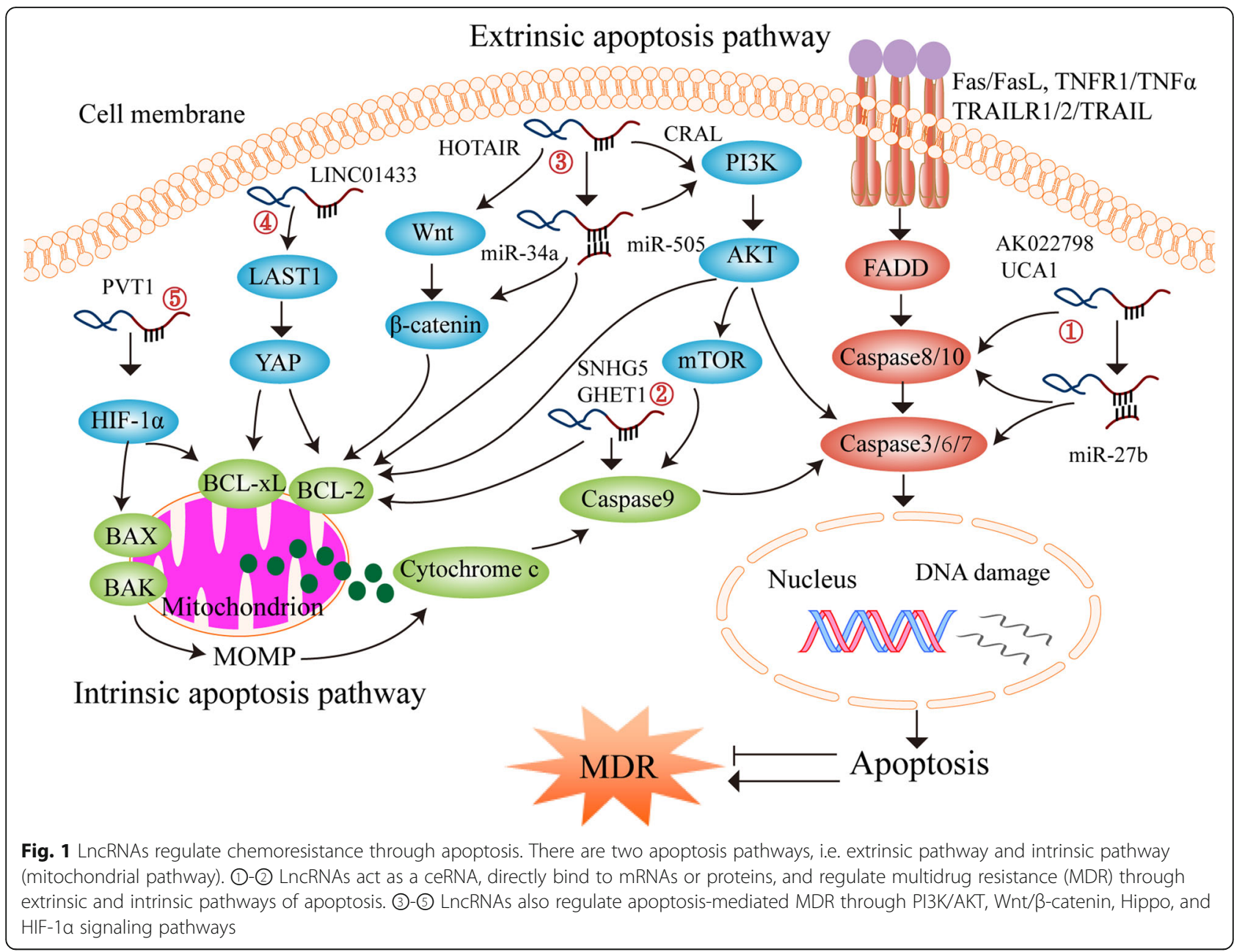

\section{PI3K/AKT signaling pathway}

The PI3K/AKT signaling pathway plays an important role in regulating apoptosis and drug resistance. The activation of PI3K/AKT pathway inhibits apoptosis, leading to tumor progression, drug resistance, and treatment failure, while inhibition of PI3K/AKT signaling reverses drug resistance by inducing apoptosis $[168,169]$. In gastric cancer, Wang et al. have reported that CRAL (cisplatin resistance-associated lncRNA) functions as a ceRNA to reverse gastric cancer DDP resistance via the miR-505/CYLD (cylindromatosis)/AKT axis [125]. It has been found that CRAL is mainly located in the cytoplasm and sponges the endogenous miR-505, consequently increasing CYLD expression, suppressing AKT activation, and enhancing the sensitivity of gastric cancer cells to DDP in vitro and in vivo [125]. Zeng et al. have reported that the knockdown of XLOC_006753 can reduce the expression levels of PI3K, p-AKT (Thr308/ Ser473), and p-mTOR (phosphorylation mechanistic target of rapamycin kinase), thus activating caspase- 9 to promote apoptosis and reverse DDP and 5-FU resistance in gastric cancer cells in vitro [127]. Cheng et al. have demonstrated that IncRNA HOTAIR (HOX transcript antisense RNA) is significantly up-regulated in gastric cancer patients and DDP-resistant cells [137]. HOTAIR has further been found to target miR-34a and activate the PI3K/AKT pathway, consequently decreasing the expression of caspase- 3 and BAX, increasing the expression of $\mathrm{BCL}-2$, inhibiting apoptosis, and inducing DDP resistance in gastric cancer cells in vitro and in vivo [137].

\section{Hippo signaling pathway}

The Hippo signaling pathway is closely associated with apoptosis and MDR by regulating its downstream effectors, Yes-associated protein (YAP) and large tumor suppressor kinase 1 (LATS1) [170]. Recent studies have shown that activation of the Hippo signaling pathway inhibits apoptosis by decreasing the BAX/BCL-2 ratio [171], whereas the downregulation of YAP expression can promote apoptosis [172]. Zhang et al. have shown that LINC01433 decreases the phosphorylation of YAP by disrupting the YAP-LATS1 association. Meanwhile, YAP directly binds to the LINC01433 promoter region and activates its transcription [130]. The formation of 
the LINC01433-YAP feedback loop suppresses apoptosis and induces resistance to doxorubicin (DOX) and DDP. It has also been found that LINC01433 knockdown significantly increases the sensitivity of gastric cancer cells to DOX and DDP [130].

\section{Wnt/ß-catenin signaling pathway}

Wnt/ $\beta$-catenin signaling pathway has been demonstrated as an important regulator of cell proliferation, differentiation, and apoptosis, and its abnormal activation is related to MDR in cancer [173, 174]. Targeting the Wnt/ $\beta$-catenin signaling pathway is a new hope for reversing cancer drug resistance $[175,176]$. Cheng et al. have reported that lncRNA HOTAIR directly binds to miR-34a, reduces its expression level, and increases the expression of Wnt and $\beta$-catenin [137]. The interference with HOTAIR can decrease the expression of Wnt and $\beta$ catenin, thereby increasing the BAX/BCL-2 ratio, activating caspase-3, promoting apoptosis, and reversing DDP resistance in gastric cancer cells in vitro and in vivo [137].

\section{HIF-1a signaling pathway}

Activation of the HIF-1 $\alpha$ signaling pathway is critical for cancer cells adapting to the hypoxic environment, which can mediate apoptosis through the mitochondrial pathway [177]. Recent studies have shown that HIF- $1 \alpha$ regulates the mitochondrial apoptosis pathway and MDR by breaking the dynamic balance between the pro-apoptotic proteins (BAX, BAK) and anti-apoptotic proteins (BCL2, BCL-xL) $[178,179]$. Zhang et al. have reported that lncRNA PVT1 is highly expressed in DDP resistant gastric cancer cells and tumor tissues from DDP resistant gastric cancer patients, up-regulates the expression of HIF- $1 \alpha$, inhibits apoptosis, and induces DDP resistance [148]. It has further been shown that silencing PVT1 can reduce the expression of HIF- $1 \alpha$ and enhance the sensitivity of gastric cancer cells to DDP [148].

\section{LncRNA-mediated EMT}

EMT is a biological process in which epithelial cells lose their polarity and transform into mesenchymal cells with the ability to move freely [115]. The expression and/or function of epithelial genes such as E-cadherin (E-cad), Claudin, cytokeratins (CKs), and zona occludens 1 (ZO1) are lost during the transition, whereas the expression levels of genes that define the mesenchymal phenotype, such as Vimentin, fibronectin, N-cadherin ( $\mathrm{N}$-cad), and matrix metalloproteinases (MMPs) are elevated [180]. The process of EMT is mainly regulated by transcription factors, including zinc-finger-binding transcription factors Snail1 and Snail2, the basic helix-loop-helix (bHLH) factors Twist1 and Twist2, and the zinc-finger E-box-binding homeobox factors ZEB1 and ZEB2 (Fig. 2)
[181]. EMT leads to the degradation of adhesion structures between tumor cells, increasing invasiveness and causing chemoresistance and treatment failure [182].

LncRNAs have recently been found to play an important role in the process of drug resistance caused by EMT [183, 184]. LncRNAs regulate EMT-mediated resistance in gastric cancer by regulating EMT markers or transcription factors (Fig. 2). Mao et al. have demonstrated that the expression of lncRNA HOTTIP is upregulated in MDR gastric cancer cells, which decreases the expression of E-cad and ZO1, increases the expression of N-cad, Vimentin, ZEB1, and Twist, and induces EMT [157]. Conversely, silencing HOTTIP can reverse EMT and enhance the sensitivity of MDR gastric cancer cells to DDP, ADR, and 5-FU in vitro [157]. Han et al. have found that IncRNA LEIGC expression is significantly down-regulated in tumor tissues from human gastric cancer patients, which causes the decreased expression of E-cad and the increased expression of Vimentin, Twist, Slug, ZEB1, and Snail, as well as EMT and resistance of gastric cancer cells to 5-FU [155]. Jia et al. have shown that lncRNA HOTAIR directly targets miR-17-5p to down-regulate E-cad expression and upregulate the expression of $\mathrm{N}$-cad and Vimentin, thereby inducing EMT and the resistance of gastric cancer cells to DDP, ADR, mitomycin (MMC), and 5-FU [138]. Guo et al. have reported that IncRNA PCAT-1 (prostate cancer associated transcript 1) is highly expressed in DDPresistant gastric cancer tissues and cells [134]. Mechanistically, PCAT-1 competitively binds to miR-128, upregulates ZEB1 expression, and induces EMT and DDP resistance [134]. Zeng et al. have reported that lncRNA XLOC_006753 expression is up-regulated in gastric cancer tissues and MDR gastric cancer cell lines, and the knockdown of XLOC_006753 can reduce the expression levels of PI3K, p-AKT (Thr308/Ser473), p-mTOR, $\beta$ catenin, Vimentin, and Snail, thus reversing EMT and enhancing the sensitivity of gastric cancer cells to DDP and 5-FU in vitro [127].

\section{LncRNA-mediated cancer cell stemness}

Cancer stem cells (CSCs) are a subset of cancer cells with the ability to self-renew and differentiate, which can lead to tumor growth, metastasis, and drug resistance [185]. CSCs play a pivotal role in drug resistance and cancer treatment failure because they have channel proteins to efflux anticancer drugs, which leads to the decreased concentration of drugs in the cells and then induces MDR [185]. The stemness markers of CSCs mainly include cluster of differentiation 24 (CD24), CD29, CD44, CD133, nanog, SRY-box transcription factor 2 (SOX2), SOX9, LIN28, OCT1/2/4, c-Myc, kruppel like factor 4 (KLF4), aldehyde dehydrogenase 1 (ALDH1), and essential specific antigen (ESA) (Fig. 3) 


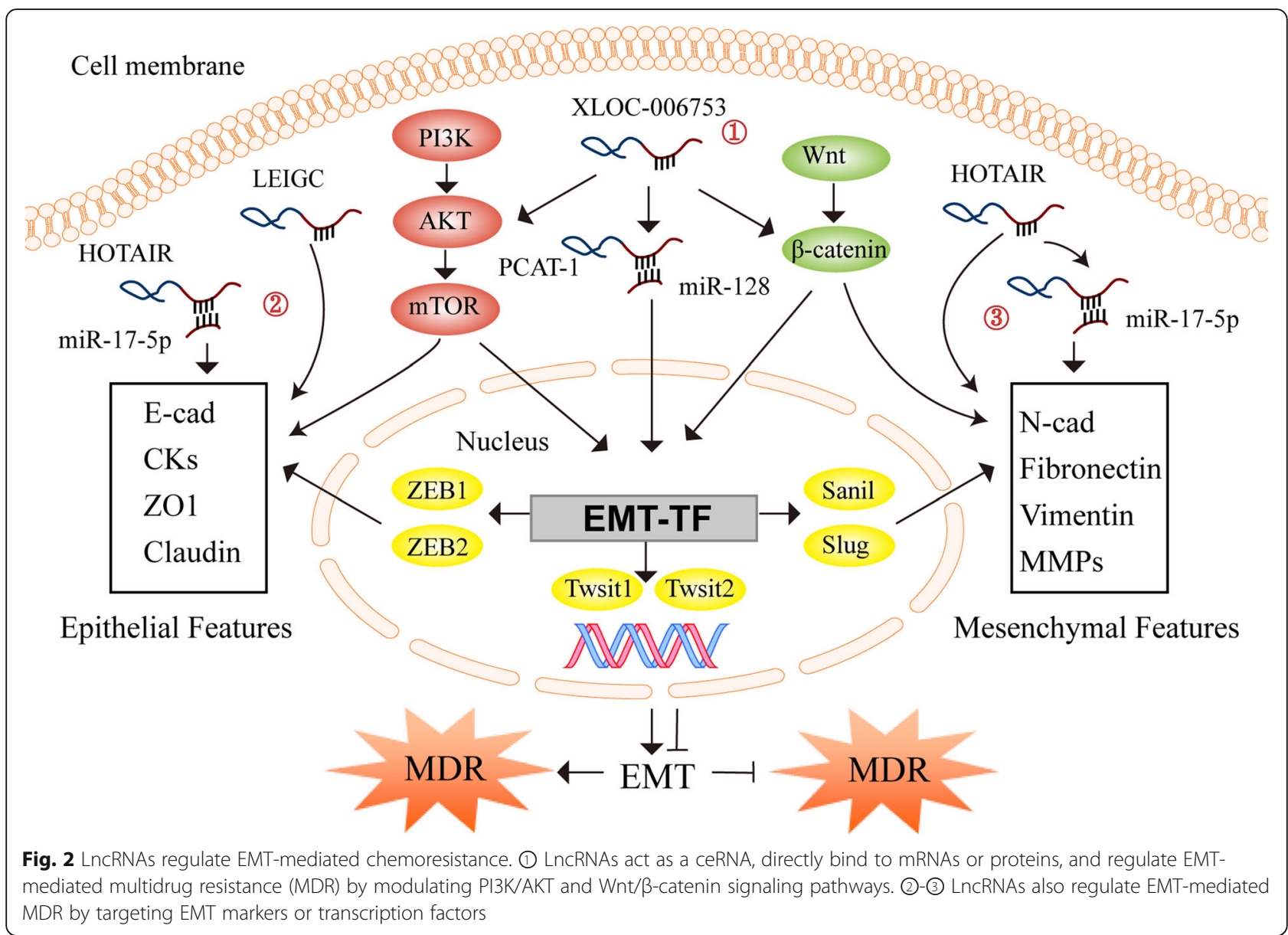

[186, 187]. The gain or loss of cancer cell stemness is regulated by the stemness-related pathways and stemness markers [188]. Therefore, targeting the cancer cell stemness-related pathways or markers is an important strategy to reverse drug resistance and enhance drug sensitivity.

LncRNAs have been reported to regulate gastric cancer cell stemness and MDR by modulating stemnessrelated pathways or markers (Fig. 3). Activation of the $W n t / \beta$-catenin pathway has been found to promote the stemness of cancer cells $[189,190]$. Wang et al. have reported that lncRNA BCAR4 (breast cancer anti-estrogen resistance 4) is highly expressed in DDP-resistant gastric cancer cells. Further studies have shown that BCAR4 activates the $\mathrm{Wnt} / \beta$-catenin signaling pathway and upregulates the expression of stemness markers nanog, OCT3/4, SOX2, c-Myc, and KLF4, which further enhance gastric cancer cell stemness and DDP resistance [153]. He et al. have found that lncRNA MACC1-AS1 (MACC1 antisense RNA 1) competitively antagonizes miR-145-5p, thereby up-regulating the levels of diacylglycerol cholinephosphotransferase (CPT1) and acetyl-
CoA synthetase (ACS) to participate in fatty acid oxidation (FAO), increasing the expression of CD133, OCT4, SOX2, and LIN28, and inducing the resistance of gastric cancer cells to 5-FU and oxaliplatin (OXA) [128]. Unsurprisingly, the knockdown of MACC1-AS1 attenuates the stemness of gastric cancer cells and reverses MDR [128]. Song et al. have shown that THOR (testis-associated highly conserved oncogenic long non-coding RNA) is highly expressed in gastric cancer tissues and cells, whereas THOR knockdown decreases the expression of SOX9 through directly binding to its 3'UTR, thus inhibiting gastric cancer cell stemness and reversing the resistance of gastric cancer cells to DDP [141]. Xiao et al. have demonstrated that lncRNA MALAT1 directly binds to SOX2 mRNA, enhances its stability, and increases its expression, which further promotes the stemness of gastric cancer cells and induces DDP resistance [121]. Wu et al. have found that IncRNA HCP5 (histocompatibility leukocyte antigen complex P5) drives FAO by sponging miR-3619-5p and promoting stemness and the resistance of gastric cancer cells to 5-FU and OXA [158]. 


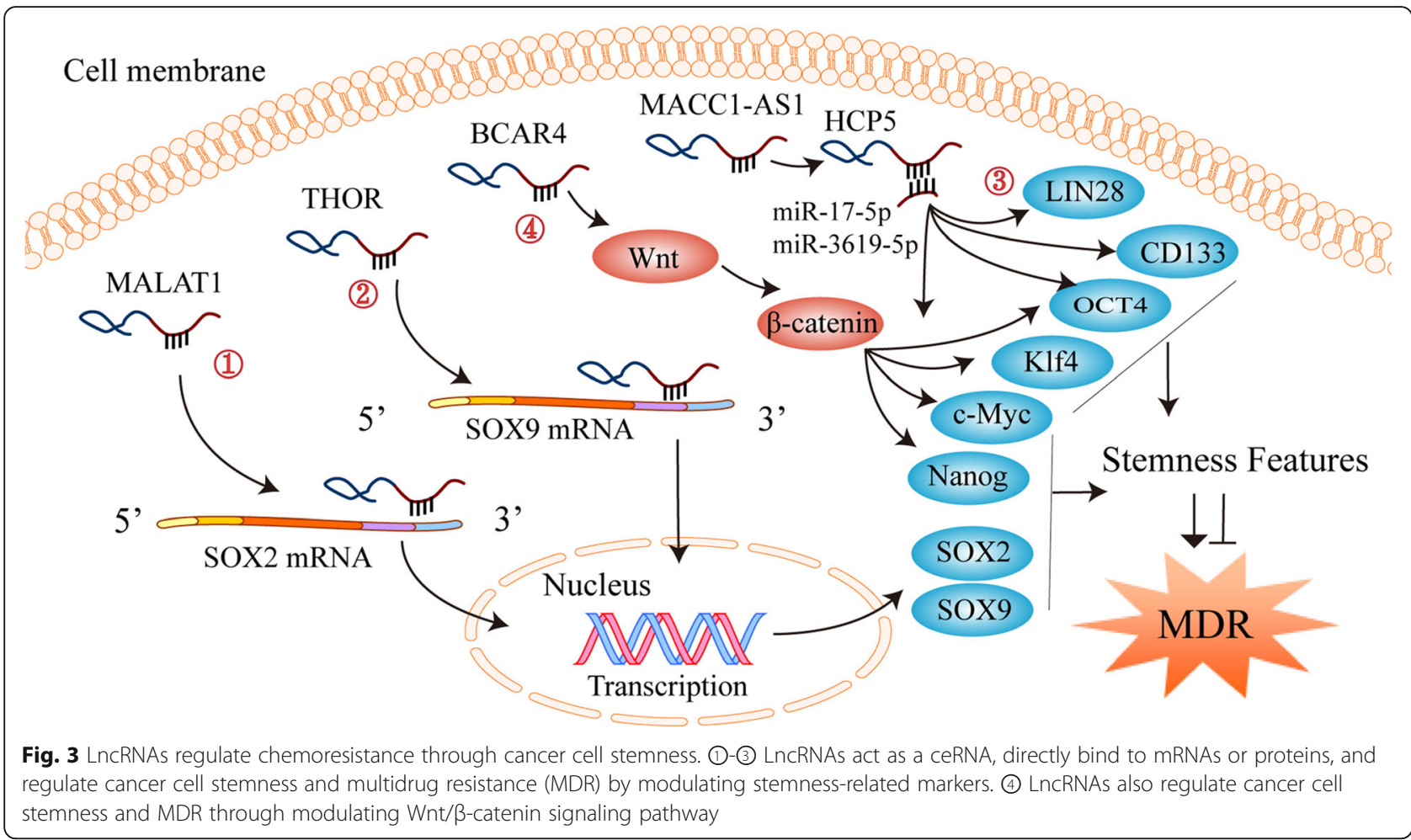

\section{LncRNA-mediated autophagy}

Autophagy is an evolutionarily conserved cellular process, through which damaged organelles and superfluous proteins are degraded, thereby maintaining the correct cellular balance [191]. The process of autophagy is divided into five distinct stages (Fig. 4): 1) initiation, 2) vesicle nucleation, 3) vesicle elongation, 4) vesicle fusion, and 5) cargo degradation [192]. Firstly, various stresses (deficiency of oxygen, ultraviolet rays, or exposure to toxic agents) trigger autophagy, and then the assembly of the Unc-51-like kinase 1 (ULK1) complex, comprising ULK1, autophagy-related genes 13 (ATG13), and ATG101 induces nucleation of the autophagy-isolation membrane. Following nucleation, the elongation of the isolation membrane is regulated by the ATG12-ATG5ATG16 complex. Moreover, the isolation membrane collects cellular materials to degrade and form an autophagosome, which is regulated by ATG8/LC3 (microtubule-associated protein 1A/1B-light chain 3) complex. Subsequently, the autophagolysosome is formed through the fusion of autophagosome and lysosome, which is mediated by Ras-related protein 7 (Rab7) and FYVE and coiled-coil protein 1 (FYCO1) transport proteins. Finally, cellular components are degraded and recycled to supply energy to the cells due to the action of hydrolytic enzymes [193].

Recent studies have shown a paradoxical role of autophagy in cancer [194]. Autophagy is a double-edged sword of cancer MDR; it not only participates in the development of MDR and protects cancer cells from chemotherapy but also promotes cell death and mediates chemosensitization in MDR cancer cells with insufficient apoptosis [195, 196]. In gastric cancer, lncRNAs are widely involved in regulating various stages of autophagy as well as autophagy-mediated MDR (Fig. 4). Hu et al. have demonstrated that IncRNA MALAT1 acts as a ceRNA for miR-23b-3p and attenuates the inhibitory effects of miR-23b-3p on ATG12 expression, thus inducing autophagy-mediated resistance of gastric cancer cells to DDP and vincristine (VCR) in vitro and in vivo [122]. It has been found that MALAT1 is highly expressed in DDP-resistant AGS and HGC-27 cells [122, 123]. MALAT1 also binds to miR-30b and increases ATG5 expression, whereas MALAT1 knockdown can suppress autophagy and enhance the chemosensitivity of gastric cancer cells $[122,123]$. Xin et al have found that IncRNA HULC interacts with forkhead box M1 (FOXM1) and stabilizes this protein, thus increasing the ratio of LC3-II/LC3-I and inducing autophagy-mediated DDP resistance [132]. As expected, silencing HULC has been shown to inhibit autophagy and enhance chemotherapy sensitivity of gastric cancer cells in vitro and in vivo [132].

\section{LncRNA regulates MDR-related genes}

Ample evidence suggests that the expression of ATPbinding cassette $(\mathrm{ABC})$ transporters, especially multidrug resistance protein 1 (MDR1, also known as P- 


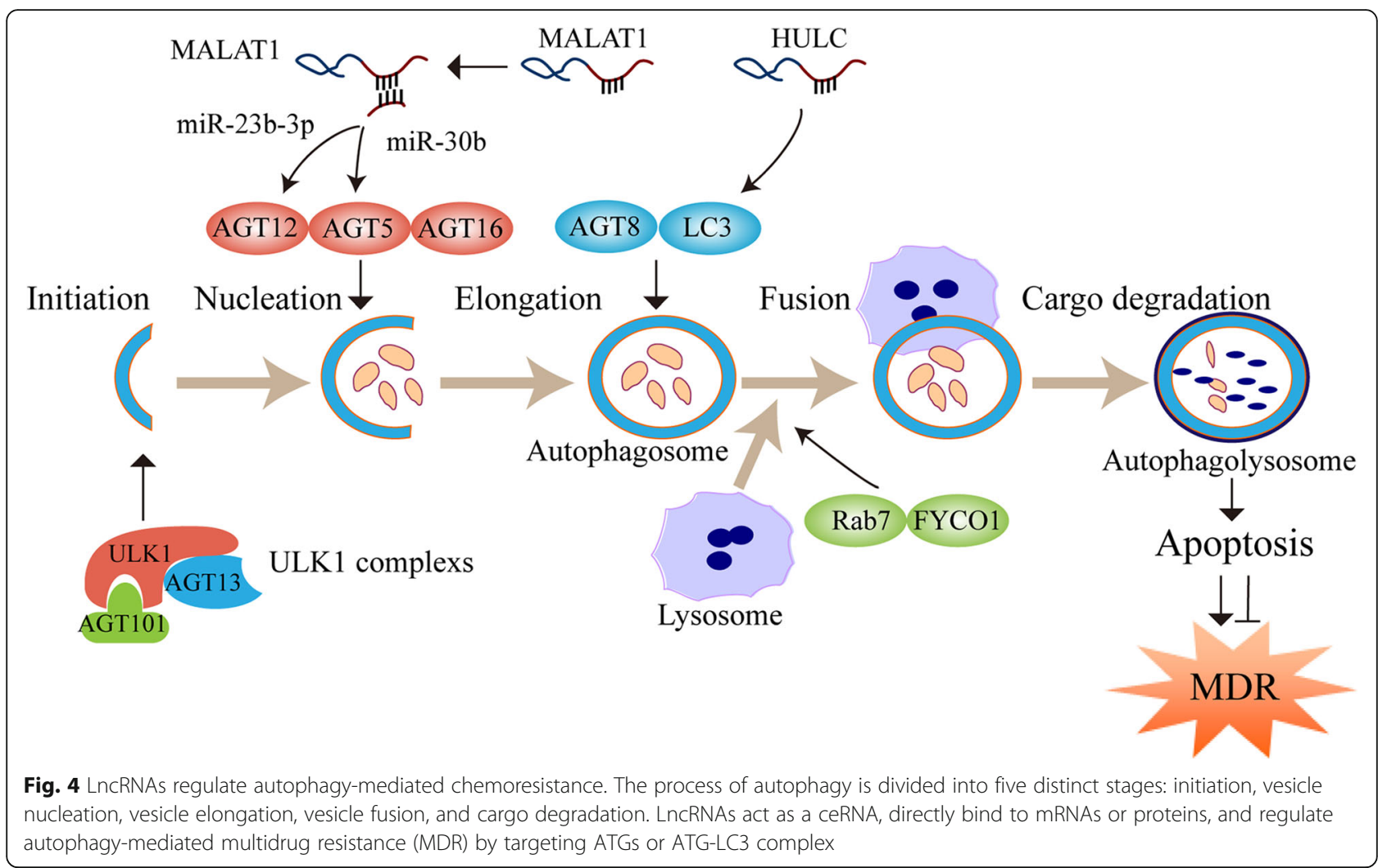

glycoprotein or P-gp) and multidrug resistanceassociated protein 1 (MRP1), which are encoded by the $\mathrm{ABC}$ subfamily $\mathrm{B}$ member 1 (ABCB1) and the $\mathrm{ABC}$ subfamily $C$ member 1 (ABCC1), respectively, confers resistance to chemotherapy [197]. The ABC transporters export chemotherapeutic drugs out of the cells, resulting in resistance with reduced concentrations of the drugs intracellularly. The transporters sequestrate intracellular drugs into membrane vesicles in the cytoplasm, which also causes chemotherapy resistance (Fig. 5) [198].

In gastric cancer, IncRNAs participate in the acquisition of chemotherapy resistance by regulating MDRrelated genes (Fig. 5). Wang et al have shown that lncRNA ROR (regulator of reprogramming) expression is positively associated with MDR and poor prognosis of patients with gastric cancer [126]. It has also been reported that ROR depletion reduces MRP1 expression and reverses resistance to ADR and VCR [126]. Wu et al have reported that IncRNA BLACAT1 (bladder cancer associated transcript 1) accelerates the OXA-resistance acquisition of gastric cancer cells by targeting miR-361 and increasing MDR1 protein expression in vitro and in vivo [142]. Moreover, Wang et al have demonstrated that MRUL (MDR-related and upregulated lncRNA) exerts an enhancer-like role in up-regulating MDR1 expression, whereas MRUL knockdown reduces MDR1 expression and reverses resistance to ADR and VCR in vitro and in vivo [149]. Shang et al have found that lncRNA CASC9 (cancer susceptibility 9) is overexpressed in BGC823 and SGC7901 cells that are resistant to paclitaxel (PTX) or ADR [156]. Further studies have shown that CASC9 knockdown decreases MDR1 expression and restores the sensitivity of gastric cancer cells to PTX and ADR in vitro [156]. It has also been found that lncRNA ANRIL (antisense noncoding RNA in the INK4 locus) is highly expressed in DDP-resistant and 5-FUresistant gastric cancer tissues and cells [144]. Importantly, ANRIL expression is positively correlated with the expression of MDR1 and MRP1 while ANRIL knockdown down-regulates the expression of MDR1 and MRP1 and reverses MDR [144]. Xu et al have shown that the overexpression of lncRNA DANCR up-regulates the expression of MDR1 and MRP1 and induces DDP resistance of gastric cancer cells in vitro [151].

\section{LncRNA-mediated epigenetic modifications}

Epigenetic modifications of histones can regulate resistance to anticancer drugs because cancer cells can develop drug resistance by reprogramming epigenetic networks to maintain their intrinsic homeostasis [199]. For example, the demethylation of H3K4 promotes DDP resistance of cancer cells while restoration of $\mathrm{H} 3 \mathrm{~K} 4$ 


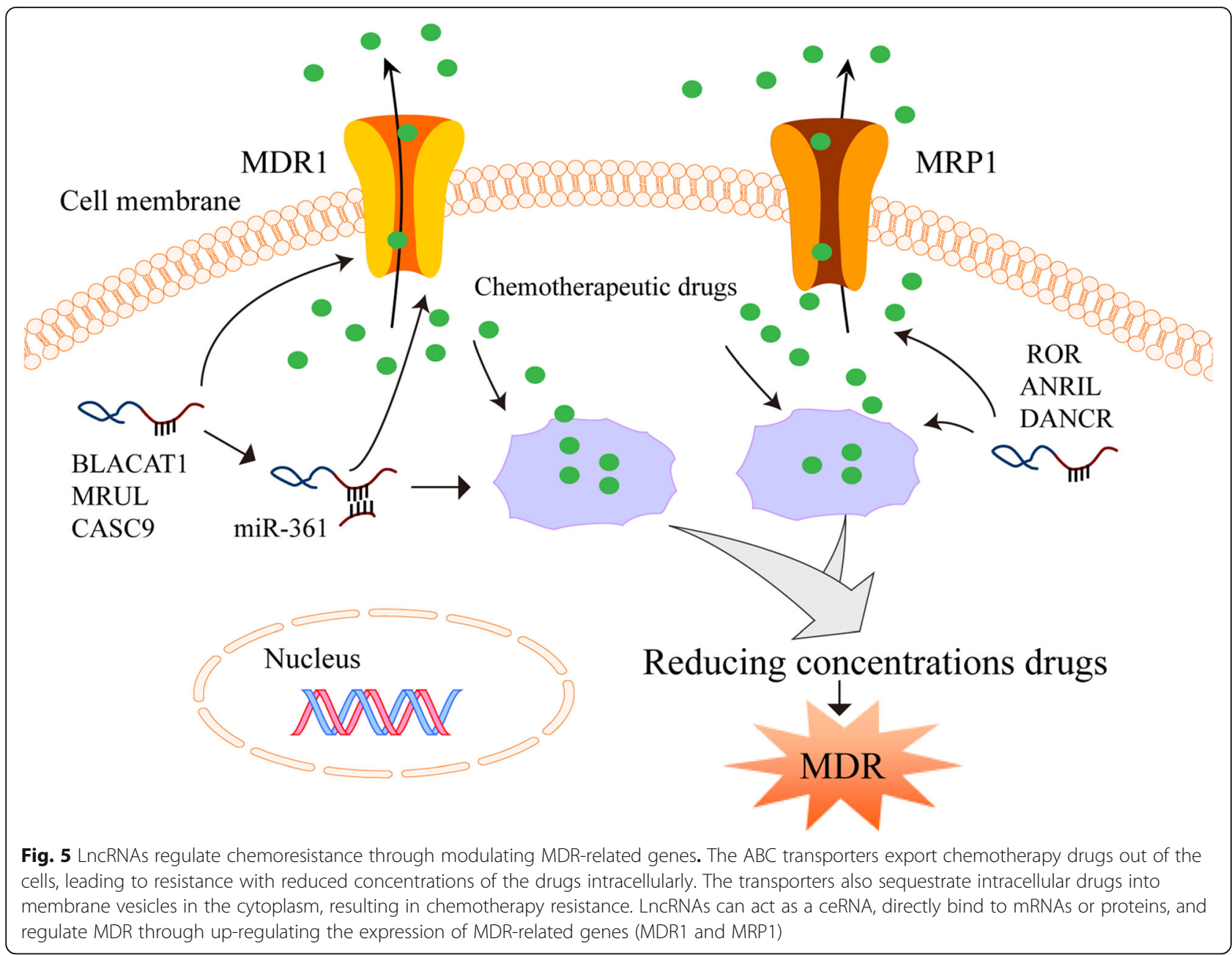

methylation reverses such resistance [200]. Further, histone deacetylases regulate the functional equilibrium of histone acetylation and deacetylation, and its dysfunction leads to chemotherapy resistance [201].

In gastric cancer, lncRNAs also contribute to chemotherapy resistance by regulating histone methylation. Ye et al have found that lncRNA HOXD-AS1 (HOXD antisense RNA 1) is highly expressed in DDP-resistant gastric cancer tissues and cells [131]. Mechanism studies have shown that HOXD-AS1 epigenetically inhibits PDCD4 expression by binding to the histone methyltransferase enhancer of zeste homologue 2 (EZH2) on the promoter of PDCD4, thus increasing $\mathrm{H} 3 \mathrm{~K} 27 \mathrm{me} 3$ level and inducing DDP resistance in gastric cancer cells [131]. Li et al have shown that IncRNA PCAT-1 epigenetically silences phosphatase and tensin homolog (PTEN) by binding to EZH2, which also increases H3K27me3 level and causes DDP resistance [135]. More importantly, the knockdown of either HOXD-AS1 or PCAT-1 enhances the sensitivity of DDP-resistant gastric cancer cells to DDP.

\section{Perspectives and future directions}

Overall, this review provides compelling evidence for lncRNAs as biomarkers for diagnosis, prognosis, and regulator of chemoresistance in gastric cancer. Because lncRNAs in the circulation (serum/plasma) or gastric juice are easy to obtain with non-invasive methods, they have great advantages as biomarkers for early screening, diagnosis, and prognosis of gastric cancer. Currently, lncRNA PCA3 in urine has been used as an early screening biomarker of prostate cancer [56, 57]. Therefore, it is of great clinical value to validate lncRNAs in serum/ plasma or gastric juice as biomarkers for gastric cancer. Considering that most of the studies cited in this review are single-center trials with small samples, the results may be biased. Next, more in-depth studies are needed to accelerate the clinical applications of lncRNAs, such as increasing the sample size or conducting multi-center research to reduce the errors caused by individual differences.

LncRNAs are also involved in the regulation of chemotherapy resistance by modulating the signaling 
pathways related to apoptosis, EMT, cancer cell stemness, and autophagy, the expression of MDR-related genes, and epigenetic modifications. Therefore, targeting lncRNAs may be a promising strategy to enhance chemosensitivity and improve the efficacy of gastric cancer chemotherapy [202]. Previous studies have shown that treatment without 5-FU significantly improves the first progression survival and overall survival of gastric cancer patients with high PVT1 expression [147]. However, the patients harboring PVT1 overexpression do not obtain survival-related benefits from 5-FU-based chemotherapy [147]. Therefore, it is of great importance to further characterize lncRNAs in liquid biopsies as a guide to precision medicine for gastric cancer patients.

There is an increasing interest in targeting lncRNAs for gastric cancer therapy. However, concerns have also been raised about the therapeutic potential of targeting a single lncRNA and the current targeting strategies. First of all, despite the great progress in understanding the structures and functions of IncRNAs since their discovery, the study of lncRNAs is still a burgeoning research field and we have only touched on the tip of this iceberg. Furthermore, given the large number of lncRNAs and their up-regulation or down-regulation in gastric cancer, it is critically needed to determine the most clinically relevant lncRNAs in this disease. Of note, lncRNAs are poorly conserved among different species. Therefore, the lncRNA-targeting strategies that are developed by utilizing various animal models and cell culture systems cannot be easily extended to human applications. The latest advances in CRISPR (clustered regularly interspaced short palindromic repeats)/Cas9 gene knockout, knockin, and point mutations may help to understand the biological role of lncRNAs. At the same time, the development of human primary cell models and patientderived tumor xenograft (PDX) animal models may be helpful for investigating the role of lncRNAs and developing lncRNA-targeting strategies. In the near future, the development of IncRNA-targeted cancer therapy seems to be very promising.

In conclusion, accumulating evidence has shown the potential of lncRNAs as biomarkers in liquid biopsies throughout the entire management process of gastric cancer, including diagnosis, selection of chemotherapeutics, monitoring of curative effects, and prognosis.

\footnotetext{
Abbreviations

5-FU: 5-fluorouracil; $A B C$ : ATP-binding cassette; $A B C B 1$ : $A B C$ subfamily $B$ member 1; $A B C C 1$ : $A B C$ subfamily $C$ member 1; $A B H D 11$ : Abhydrolase domain containing 11; ABHD11-AS1: ABHD11 antisense RNA 1; ACS: AcetylCoA synthetase; ADR: Adriamycin; AFP: Alpha fetoprotein; AKT: serine/ threonine protein kinase B; ALDH1: Aldehyde dehydrogenase 1;

ANRIL: Antisense noncoding RNA in the INK4 locus; AOC4P: Amine oxidase copper containing 4, pseudogene; ARHGAP27P1: Rho GTPase activating protein 27 pseudogene 1; ATG: Autophagy-related genes; AUC: Area under curve; B3GALT5: Beta-1,3-galactosyltransferase 5; B3GALT5-AS1: B3GALT5 antisense RNA 1; BAK: BCL-2 antagonist/killer; BANCR: BRAF-activated non-
}

protein coding RNA; BAX: BCL-2 associated $X$, apoptosis regulator; BCAR4: Breast cancer anti-estrogen resistance 4; BCL-2: B-cell lymphoma-2; BCL-xL: B-cell lymphoma-extra large; BLACAT1: Bladder cancer associated transcript 1; C5orf66-AS1: C5orf66 antisense RNA 1; CA: Carbohydrate antigen; CASC: Cancer susceptibility; CCAT2: Colon cancer associated transcript 2; CD: Cluster of differentiation; $\mathrm{CDH1}$ : Cadherin 1;

CEA: Carcinoembryonic antigen; CEBPA: CCAAT enhancer binding protein alpha; CEBPA-AS1: CEBPA divergent transcript; CeRNA: Competitive endogenous RNA; circRNAs: Circular RNAs; CKs: Cytokeratins; c-Myc/ MYC: MYC proto-oncogene, bHLH transcription factor; CPT1: Diacylglycerol cholinephosphotransferase; CRAL: Cisplatin resistance-associated IncRNA; CRISPR: Clustered regularly interspaced short palindromic repeats; CSCs: Cancer stem cells; CTDHUT: CTD highly upregulated transcript; CYLD: Cylindromatosis; DANCR: Differentiation antagonizing non-protein coding RNA; DDP: Cisplatin; DGCR5: DiGeorge syndrome critical region gene 5; DOX: Doxorubicin; E-cad: E-cadherin; EMT: Epithelial-mesenchymal transition; ESA: Essential specific antigen; EZH2: Enhancer of zeste homologue 2; FADD: FAS-associated death domain protein; FAM49B: Family with sequence similarity 49, member B; FAM49B-AS: FAM49B antisense RNA; FAM84B: Family with sequence similarity 84, member B; FAM84B-AS: FAM84B antisense RNA; FAO: Fatty acid oxidation; FAS: Fas cell surface death receptor; FASL: FAS ligand; FOXD2: Forkhead box D2; FOXD2-AS1: FOXD2 adjacent opposite strand RNA 1; FOXFOXMM1: Forkhead box M1; FYCO1: FYVE and coiled-coil protein 1; GACAT2: Gastric cancer associated transcript 2; GASL1: Growth arrest associated IncRNA 1; GHET1: Gastric carcinoma proliferation enhancing transcript 1; GNAQ-6:1: G protein subunit alpha q-6:1; GUSBP11: GUSB pseudogene 11; H19: H19 imprinted maternally expressed transcript; HCP5: Histocompatibility leukocyte antigen complex P5; HIF-1a: Hypoxiainducible factor-1a; HOTAIR: HOX transcript antisense RNA; HOTTIP: HOXA distal transcript antisense RNA; HOXA11: Homeobox A11; HOXA11-

AS: HOXA11 antisense RNA; HOXD: Homeobox D cluster; HOXD-AS1: HOXD antisense RNA; HULC: Hepatocellular carcinoma upregulated long noncoding RNA; INHBA: Inhibin subunit beta A; INHBA-AS1: INHBA antisense RNA 1; KLF4: Kruppel Like Factor 4; LATS1: Large tumor suppressor kinase 1; LC3: Microtubule associated protein 1 light chain 3 alpha;

LEIGC: LncRNAchr2:118381039-118,383,698; LincRNAs: Intergenic IncRNAs; LncRNAs: Long non-coding RNAs; MACC1: MET transcriptional regulator MACC1; MACC1-AS1: MACC1 antisense RNA 1; MALAT1: Metastasis associated lung adenocarcinoma transcript 1; MDR: Multidrug resistance; MDR1: Multidrug resistance protein 1; MEF2C: Myocyte enhancer factor 2C; MEF2C-AS1: MEF2C antisense RNA 1; MEF2D: Myocyte enhancer factor 2D; MEG3: Maternally expressed 3; MIR4435-2HG: MIR4435-2 host gene; MIAT: Myocardial infarction associated transcript; miRNAs: microRNAs; MMC: Mitomycin; MMPs: Matrix metalloproteinases; MNX1: Motor neuron and pancreas homeobox 1; MNX1-AS1: MNX1 antisense RNA 1; MOM: Mitochondrial outer membrane; MOMP: Mitochondrial outer membrane permeability; MRP1: Multidrug resistance-associated protein 1; MRUL: MDR-related and upregulated InCRNA; MT1JP: Metallothionein $1 \mathrm{~J}$, pseudogene; mTOR: Mechanistic target of rapamycin kinase; N-cad: Ncadherin; ncRNAs: Noncoding RNAs; NEAT1: Nuclear paraspeckle assembly transcript 1; NSE: Neuron-specific enolase; OCT: Organic cation/carnitine transporter; OS: Overall survival; OXA: Oxaliplatin; PANDAR: Promoter of CDKN1A antisense DNA damage activated RNA; PARP: Poly-(ADP-ribose) polymerase; PCA3: Prostate cancer associated 3; PCAT1: Prostate cancer associated transcript 1; PDCD4: Programmed cell death 4; PDX: Patientderived tumor xenograft; P-gp: P-glycoprotein; PI3K: Phosphatidylinositol 3kinase; PCSK2-2:1: Proprotein convertase subtilisin/kexin type 2-2:1; PTCSC3: Papillary thyroid carcinoma susceptibility candidate 3; PTEN: Phosphatase and tensin homolog; PTX: Paclitaxel; PVT1: Plasmacytoma variant translocation 1; Rab7: Ras-related protein 7; RMRP: RNA component of mitochondrial RNA processing endoribonuclease; ROC: Receiver operator characteristic curve; ROR: Regulator of reprogramming; SMARCC2: SWI/SNF related, matrix associated, actin dependent regulator of chromatin subfamily c member 2; SNHG: Small nucleolar RNA host gene; snoRNAs: Small nucleolar RNAs; SOX: SRY-box transcription factor; THOR: Testis-associated highly conserved oncogenic long non-coding RNA; TINCR: Terminal differentiation-induced ncRNA; TNFR1: Tumor necrosis factor receptor 1; TNFa: Tumor necrosis factor alpha; TNM: Tumor, node, metastasis; TRAIL: TNF-related apoptosis-inducing ligand; TRAILR1/2: TRAIL cell surface receptors 1 and 2; TUBA4B: Tubulin alpha 4b; TUG1: Taurine up-regulated 1 ; UCA1: Urothelial cancer associated 1; UEGC1: ENST00000568893.1; 
UEGC2: ENST00000378432.1; ULK1: Unc-51-like kinase 1; USP9X: Ubiquitin specific peptidase 9 X-linked; UTR: Untranslated regions; VCR: Vincristine; XIST: X inactive specific transcript; YAP: Yes-associated protein; ZEB1: Zinc finger E-box binding homeobox 1; ZFAS1: ZNFX1 antisense RNA 1; ZNFX1: Zinc finger NFX1-type containing 1; ZO1: Zona occludens 1

\section{Acknowledgements}

We thank the current and former members of our laboratories and collaborators for their contributions to the publications cited in this review article. The research field in IncRNA is rapidly growing, and we apologize for not being able to cite all the recent publications, due to space limitation.

\section{Authors' contributions}

JJQ and XDC conceptualized the manuscript. SMR and SWM collected the literature. LY and ZYX collected the literature, wrote the manuscript, and made the figures. JJQ and XDC edited and made significant revisions to the manuscript. All authors read and approved the final manuscript.

\section{Funding}

This study was supported by National Natural Science Foundation of China (81903842, 81573953, 81703753, 81973634), Zhejiang Chinese Medical University Startup Funding (111100E014), Zhejiang Provincial Science and Technology Projects (2018C37045), Natural Science Foundation of Zhejiang Province (LY18H290006), Zhejiang Provincial Medical and Healthy Science and Technology Projects (WKJ-ZJ-1728, 2016KYB220), and Program of Zhejiang Provincial TCM Sci-tech Plan (2016ZZ012, 2018ZY006, 2018ZB044, 2019ZZO10, 2020ZZ005).

\section{Availability of data and materials}

Not applicable.

\section{Ethics approval and consent to participate}

Not applicable.

\section{Consent for publication}

Not applicable.

\section{Competing interests}

The authors declare that they have no competing interests.

\section{Author details}

${ }^{1}$ The First Affiliated Hospital of Zhejiang Chinese Medical University, Hangzhou 310006, China. ${ }^{2}$ Institute of Cancer and Basic Medicine, Chinese Academy of Sciences, Cancer Hospital of the University of Chinese Academy of Sciences, Zhejiang Cancer Hospital, Banshan Road 1\#, Gongshu District, Hangzhou 310022, China. ${ }^{3}$ College of Pharmaceutical Sciences, Zhejiang Chinese Medical University, 548 Binwen Road, Binjiang District, Hangzhou 310053, China.

\section{Received: 16 April 2020 Accepted: 21 May 2020}

\section{Published online: 27 May 2020}

\section{References}

1. Fitzmaurice $C$, Abate D, Abbasi N, Abbastabar H, Abd-Allah F, AbdelRahman O, Abdelalim A, Abdoli A, Abdollahpour I, Abdulle ASM, et al. Global, Regional, and National Cancer Incidence, Mortality, Years of Life Lost, Years Lived With Disability, and Disability-Adjusted Life-Years for 29 Cancer Groups, 1990 to 2017: A systematic analysis for the global burden of disease study. JAMA Oncol. 2019:5:1749.

2. Thrift AP, El-Serag HB. Burden of gastric Cancer. Clin Gastroenterol Hepatol. 2020;18:534-42

3. Ham IH, Oh HJ, Jin H, Bae CA, Jeon SM, Choi KS, Son SY, Han SU, Brekken RA, Lee D, Hur H. Targeting interleukin-6 as a strategy to overcome stromainduced resistance to chemotherapy in gastric cancer. Mol Cancer. 2019;18:68.

4. Wagner AD, Syn NL, Moehler M, Grothe W, Yong WP, Tai BC, Ho J, Unverzagt S. Chemotherapy for advanced gastric cancer. Cochrane Database Syst Rev. 2017;8:Cd004064.

5. Biagioni A, Skalamera I, Peri S, Schiavone N, Cianchi F, Giommoni E, Magnelli L, Papucci L. Update on gastric cancer treatments and gene therapies. Cancer Metastasis Rev. 2019;38:537-48.
6. Yu J, Zheng W. An alternative method for screening gastric Cancer based on serum levels of CEA, CA19-9, and CA72-4. J Gastrointest Cancer. 2018;49:57-62.

7. Shimada H, Noie T, Ohashi M, Oba K, Takahashi Y. Clinical significance of serum tumor markers for gastric cancer: a systematic review of literature by the task force of the Japanese gastric Cancer association. Gastric Cancer. 2014;17:26-33.

8. He CZ, Zhang KH, Li Q, Liu XH, Hong Y, Lv NH. Combined use of AFP, CEA, CA125 and CAl9-9 improves the sensitivity for the diagnosis of gastric cancer. BMC Gastroenterol. 2013;13:87.

9. Hu PJ, Chen MY, Wu MS, Lin YC, Shih PH, Lai CH, Lin HJ. Clinical evaluation of CA72-4 for screening gastric Cancer in a healthy population: a multicenter retrospective study. Cancers (Basel). 2019;11:733.

10. Suzuki T, Kitagawa $Y$, Nankinzan R, Yamaguchi T. Early gastric cancer diagnostic ability of ultrathin endoscope loaded with laser light source. World J Gastroenterol. 2019;25:1378-86.

11. Necula L, Matei L, Dragu D, Neagu Al, Mambet C, Nedeianu S, Bleotu C, Diaconu CC, Chivu-Economescu M. Recent advances in gastric cancer early diagnosis. World J Gastroenterol. 2019;25:2029-44.

12. Zhuo W, Liu Y, Li S, Guo D, Sun Q, Jin J, Rao X, Li M, Sun M, Jiang M, et al. Long Noncoding RNA GMAN, Up-regulated in Gastric Cancer Tissues, Is Associated With Metastasis in Patients and Promotes Translation of Ephrin A1 by Competitively Binding GMAN-AS. Gastroenterology. 2019;156:676-91 e611.

13. Zhang E, He X, Zhang C, Su J, Lu X, Si X, Chen J, Yin D, Han L, De W. A novel long noncoding RNA HOXC-AS3 mediates tumorigenesis of gastric cancer by binding to YBX1. Genome Biol. 2018;19:154.

14. Shuai Y, Ma Z, Liu W, Yu T, Yan C, Jiang H, Tian S, Xu T, Shu Y. TEAD4 modulated LnCRNA MNX1-AS1 contributes to gastric cancer progression partly through suppressing BTG2 and activating BCL2. Mol Cancer. 2020;19:6.

15. Xu W, Zhou G, Wang H, Liu Y, Chen B, Chen W, Lin C, Wu S, Gong A, Xu M. Circulating IncRNA SNHG11 as a novel biomarker for early diagnosis and prognosis of colorectal cancer. Int J Cancer. 2020;146:2901-12.

16. Zhou R, Sun H, Zheng S, Zhang J, Zeng D, Wu J, Huang Z, Rong X, Bin J, Liao $Y$, et al. A stroma-related IncRNA panel for predicting recurrence and adjuvant chemotherapy benefit in patients with early-stage colon cancer. J Cell Mol Med. 2020;24:3229-41.

17. Yang Q, Li K, Huang X, Zhao C, Mei Y, Li X, Jiao L. Yang H: IncRNA SLC7A11-AS1 promotes Chemoresistance by blocking SCF (beta-TRCP)-mediated degradation of NRF2 in pancreatic Cancer. Mol Ther Nucleic Acids. 2020;19:974-85.

18. Huan L, Guo T, Wu Y, Xu L, Huang S, Xu Y, Liang L, He X. Hypoxia induced LUCAT1/PTBP1 axis modulates cancer cell viability and chemotherapy response. Mol Cancer. 2020;19:11.

19. Gu N, Wang X, Di Z, Xiong J, Ma Y, Yan Y, Qian Y, Zhang Q, Yu J. Silencing IncRNA FOXD2-AS1 inhibits proliferation, migration, invasion and drug resistance of drug-resistant glioma cells and promotes their apoptosis via microRNA-98-5p/CPEB4 axis. Aging (Albany NY). 2019;11:10266-83.

20. Ghafouri-Fard S, Taheri M. Long non-coding RNA signature in gastric cancer. Exp Mol Pathol. 2019;113:104365.

21. Virgilio E, Giarnieri E, Giovagnoli MR, Montagnini M, Proietti A, D'Urso R, Mercantini P, Balducci G, Cavallini M. Long non-coding RNAs in the gastric juice of gastric cancer patients. Pathol Res Pract. 2018;214:1239-46.

22. Zong W, Ju S, Jing R, Cui M. Long non-coding RNA-mediated regulation of signaling pathways in gastric cancer. Clin Chem Lab Med. 2018;56:1828-37.

23. Nasrollahzadeh-Khakiani M, Emadi-Baygi M, Schulz WA, Nikpour P. Long noncoding RNAs in gastric cancer carcinogenesis and metastasis. Brief Funct Genomics. 2017;16:129-45.

24. Sun W, Yang $Y, X u C$, Xie $Y$, Guo J. Roles of long noncoding RNAs in gastric cancer and their clinical applications. J Cancer Res Clin Oncol. 2016;142:2231-7.

25. The ENCODE Project Consortium. An integrated encyclopedia of DNA elements in the human genome. Nature. 2012;489:57-74.

26. Liao Q, Shen J, Liu J, Sun X, Zhao G, Chang Y, Xu L, Li X, Zhao Y, Zheng H, et al. Genome-wide identification and functional annotation of plasmodium falciparum long noncoding RNAs from RNA-seq data. Parasitol Res. 2014; 113:1269-81.

27. Johnsson P, Lipovich L, Grander D, Morris KV. Evolutionary conservation of long non-coding RNAs; sequence, structure, function. Biochim Biophys Acta. 1840;2014:1063-71.

28. Ma L, Bajic VB, Zhang Z. On the classification of long non-coding RNAs. RNA Biol. 2013;10:925-33 
29. Alessio E, Bonadio RS, Buson L, Chemello F, Cagnin S. A single cell but many different transcripts: a journey into the world of long non-coding RNAs. Int J Mol Sci. 2020;21:302.

30. Mondal T, Juvvuna PK, Kirkeby A, Mitra S, Kosalai ST, Traxler L, Hertwig F, Wernig-Zorc S, Miranda C, Deland L, et al. Sense-Antisense IncRNA Pair Encoded by Locus 6p22.3 Determines Neuroblastoma Susceptibility via the USP36-CHD7-SOX9 Regulatory Axis. Cancer Cell. 2018;33:417-34 e417.

31. Kapranov P, Cheng J, Dike S, Nix DA, Duttagupta R, Willingham AT, Stadler PF, Hertel J, Hackermuller J, Hofacker IL, et al. RNA maps reveal new RNA classes and a possible function for pervasive transcription. Science. 2007; 316:1484-8.

32. Katsel P, Roussos P, Fam P, Khan S, Tan W, Hirose T, Nakagawa S, Pletnikov MV, Haroutunian $V$. The expression of long noncoding RNA NEAT1 is reduced in schizophrenia and modulates oligodendrocytes transcription. NPJ Schizophr. 2019;5:3.

33. Zhang B, Arun G, Mao YS, Lazar Z, Hung G, Bhattacharjee G, Xiao X, Booth $\mathrm{CJ}, \mathrm{Wu}$ J, Zhang C, Spector DL. The IncRNA Malat1 is dispensable for mouse development but its transcription plays a cis-regulatory role in the adult. Cell Rep. 2012;2:111-23.

34. McHugh CA, Chen CK, Chow A, Surka CF, Tran C, McDonel P, Pandya-Jones A, Blanco M, Burghard C, Moradian A, et al. The Xist IncRNA interacts directly with SHARP to silence transcription through HDAC3. Nature. 2015;521:232-6.

35. Du Z, Sun T, Hacisuleyman E, Fei T, Wang X, Brown M, Rinn JL, Lee MG, Chen Y, Kantoff PW, Liu XS. Integrative analyses reveal a long noncoding RNA-mediated sponge regulatory network in prostate cancer. Nat Commun. 2016;7:10982.

36. Shang $A Q$, Wang WW, Yang YB, Gu CZ, Ji P, Chen C, Zeng BJ, Wu JL, Lu WY, Sun ZJ, Li D. Knockdown of long noncoding RNA PVT1 suppresses cell proliferation and invasion of colorectal cancer via upregulation of microRNA214-3p. Am J Physiol Gastrointest Liver Physiol. 2019;317:G222-g232.

37. Bianchessi V, Badi I, Bertolotti M, Nigro P, D'Alessandra Y, Capogrossi MC, Zanobini M, Pompilio G, Raucci A, Lauri A. The mitochondrial IncRNA ASncmtRNA-2 is induced in aging and replicative senescence in endothelial cells. J Mol Cell Cardiol. 2015;81:62-70.

38. Mathieu EL, Belhocine M, Dao LT, Puthier D. Spicuglia S: [functions of IncRNA in development and diseases]. Med Sci (Paris). 2014;30:790-6.

39. Dallner OS, Marinis JM, Lu YH, Birsoy K, Werner E, Fayzikhodjaeva G, Dill BD, Molina $\mathrm{H}$, Moscati A, Kutalik Z, et al. Dysregulation of a long noncoding RNA reduces leptin leading to a leptin-responsive form of obesity. Nat Med. 2019;25:507-16.

40. Westra HJ, Martinez-Bonet M, Onengut-Gumuscu S, Lee A, Luo Y, Teslovich N, Worthington J, Martin J, Huizinga T, Klareskog L, et al. Fine-mapping and functional studies highlight potential causal variants for rheumatoid arthritis and type 1 diabetes. Nat Genet. 2018;50:1366-74.

41. Wang CY, Colognori D, Sunwoo H, Wang D, Lee JT. PRC1 collaborates with SMCHD1 to fold the X-chromosome and spread Xist RNA between chromosome compartments. Nat Commun. 2019;10:2950.

42. Huang M, Wang H, Hu X. Cao X: IncRNA MALAT1 binds chromatin remodeling subunit BRG1 to epigenetically promote inflammation-related hepatocellular carcinoma progression. Oncoimmunology. 2019;8:e1518628.

43. Xiu B, Chi Y, Liu L, Chi W, Zhang Q, Chen J, Guo R, Si J, Li L, Xue J, et al. LINC02273 drives breast cancer metastasis by epigenetically increasing AGR2 transcription. Mol Cancer. 2019;18:187.

44. Wang W, Hu W, Wang Y, An Y, Song L, Shang P, Yue Z. Long non-coding RNA UCA1 promotes malignant phenotypes of renal cancer cells by modulating the miR-182-5p/DLL4 axis as a ceRNA. Mol Cancer. 2020;19:18.

45. Barlebo Ahlborn L, Ostrup O. Toward liquid biopsies in cancer treatment: application of circulating tumor DNA. Apmis. 2019;127:329-36.

46. Zuo Z, Hu H, Xu Q, Luo X, Peng D, Zhu K, Zhao Q, Xie Y, Ren J. BBCancer: an expression atlas of blood-based biomarkers in the early diagnosis of cancers. Nucleic Acids Res. 2020;48:D789-d796.

47. Zhan Y, Du L, Wang L, Jiang X, Zhang S, Li J, Yan K, Duan W, Zhao Y, Wang $L$, et al. Expression signatures of exosomal long non-coding RNAs in urine serve as novel non-invasive biomarkers for diagnosis and recurrence prediction of bladder cancer. Mol Cancer. 2018;17:142.

48. Xie Z, Zhou F, Yang Y, Li L, Lei Y, Lin X, Li H, Pan X, Chen J, Wang G, et al. Lnc-PCDH9-13:1 is a hypersensitive and specific biomarker for early hepatocellular carcinoma. EBioMedicine. 2018:33:57-67.

49. Shao Y, Ye M, Li Q, Sun W, Ye G, Zhang X, Yang Y, Xiao B, Guo J. LncRNARMRP promotes carcinogenesis by acting as a miR-206 sponge and is used as a novel biomarker for gastric cancer. Oncotarget. 2016;7:37812-24.
50. Darbandi M, Darbandi S, Agarwal A, Baskaran S, Dutta S, Sengupta P, Khorram Khorshid HR, Esteves S, Gilany K, Hedayati M, et al. Reactive oxygen species-induced alterations in H19-lgf2 methylation patterns, seminal plasma metabolites, and semen quality. J Assist Reprod Genet. 2019;36:241-53.

51. Lin $Y$, Leng $Q$, Zhan $M$, Jiang F. A plasma long noncoding RNA signature for early detection of lung Cancer. Transl Oncol. 2018;11:1225-31.

52. Ozgur E, Ferhatoglu F, Sen F, Saip P, Gezer U. Circulating IncRNA H19 may be a useful marker of response to neoadjuvant chemotherapy in breast cancer. Cancer Biomark. 2020;27:11-7.

53. Fang C, Zan J, Yue B, Liu C, He C, Yan D. Long non-coding ribonucleic acid zinc finger antisense 1 promotes the progression of colonic cancer by modulating ZEB1 expression. J Gastroenterol Hepatol. 2017;32:1204-11.

54. Arantes L, De Carvalho AC, Melendez ME, Lopes Carvalho A. Serum, plasma and saliva biomarkers for head and neck cancer. Expert Rev Mol Diagn. 2018;18:85-112.

55. Gomes CC, de Sousa SF, Calin GA, Gomez RS. The emerging role of long noncoding RNAs in oral cancer. Oral Surg Oral Med Oral Pathol Oral Radiol. 2017;123:235-41.

56. Groskopf J, Aubin SM, Deras IL, Blase A, Bodrug S, Clark C, Brentano S, Mathis J, Pham J, Meyer T, et al. APTIMA PCA3 molecular urine test: development of a method to aid in the diagnosis of prostate cancer. Clin Chem. 2006:52:1089-95.

57. Lemos AEG, Matos ADR, Ferreira LB, Gimba ERP. The long non-coding RNA PCA3: an update of its functions and clinical applications as a biomarker in prostate cancer. Oncotarget. 2019;10:6589-603.

58. Selth LA, Roberts MJ, Chow CW, Marshall VR, Doi SA, Vincent AD, Butler LM, Lavin MF, Tilley WD, Gardiner RA. Human seminal fluid as a source of prostate cancer-specific microRNA biomarkers. Endocr Relat Cancer. 2014:21:L17-21.

59. Henriksen K, O'Bryant SE, Hampel H, Trojanowski JQ, Montine TJ, Jeromin A, Blennow K, Lonneborg A, Wyss-Coray T, Soares H, et al. The future of bloodbased biomarkers for Alzheimer's disease. Alzheimers Dement. 2014;10:115-31.

60. Wang J, Yang K, Yuan W, Gao Z. Determination of serum Exosomal H19 as a noninvasive biomarker for bladder Cancer diagnosis and prognosis. Med Sci Monit. 2018;24:9307-16.

61. Zhang G, Xu Y, Zou C, Tang Y, Lu J, Gong Z, Ma G, Zhang W, Jiang P. Long noncoding RNA ARHGAP27P1 inhibits gastric cancer cell proliferation and cell cycle progression through epigenetically regulating p15 and p16. Aging (Albany NY). 2019;11:9090-110.

62. Tang $X, Y u L$, Bao J, Jiang P, Yan F. Function of long noncoding RNA UCA1 on gastric Cancer cells and its Clinicopathological significance in plasma. Clin Lab. 2019;65.

63. Giraldez MD, Spengler RM, Etheridge A, Goicochea AJ, Tuck M, Choi SW, Galas DJ, Tewari M. Phospho-RNA-seq: a modified small RNA-seq method that reveals circulating mRNA and IncRNA fragments as potential biomarkers in human plasma. EMBO J. 2019;38:e101695.

64. Xu Y, Zhang G, Zou C, Zhang H, Gong Z, Wang W, Ma G, Jiang P, Zhang W. LncRNA MT1JP suppresses gastric Cancer cell proliferation and migration through MT1.JP/MiR-214-3p/RUNX3 Axis. Cell Physiol Biochem. 2018:46:2445-59.

65. Lin LY, Yang L, Zeng Q, Wang L, Chen ML, Zhao ZH, Ye GD, Luo QC, Lv PY, Guo QW, et al. Tumor-originated exosomal InCUEGC1 as a circulating biomarker for early-stage gastric cancer. Mol Cancer. 2018;17:84.

66. Zhang K, Shi H, Xi H, Wu X, Cui J, Gao Y, Liang W, Hu C, Liu Y, Li J, et al. Genome-wide IncRNA microarray profiling identifies novel circulating IncRNAs for detection of gastric Cancer. Theranostics. 2017;7:213-27.

67. Zhou Q, Li H, Jing J, Yuan Y, Sun L. Evaluation of C5orf66-AS1 AS a potential biomarker for predicting early gastric Cancer and its role in gastric carcinogenesis. Onco Targets Ther. 2020;13:2795-805.

68. Zhang G, Chi N, Lu Q, Zhu D, Zhuang Y. LnCRNA PTCSC3 is a biomarker for the treatment and prognosis of gastric Cancer. Cancer Biother Radiopharm. 2020;35:77-81.

69. Guo J, Li Y, Duan H, Yuan L. LncRNA TUBA4B functions as a competitive endogenous RNA to inhibit gastric cancer progression by elevating PTEN via sponging miR-214 and miR-216a/b. Cancer Cell Int. 2019;19:156.

70. Ji B, Huang Y, Gu T, Zhang L, Li G, Zhang C. Potential diagnostic and prognostic value of plasma long noncoding RNA LINC00086 and miR-214 expression in gastric cancer. Cancer Biomark. 2019;24:249-55.

71. Xu Y, Zhang G, Zou C, Gong Z, Wang S, Liu J, Ma G, Liu X, Zhang W, Jiang $P$. Long noncoding RNA DGCR5 suppresses gastric cancer progression by 
acting as a competing endogenous RNA of PTEN and BTG1. J Cell Physiol. 2019;234:11999-2010.

72. Zhang G, Xu Y, Wang S, Gong Z, Zou C, Zhang H, Ma G, Zhang W, Jiang P. LncRNA SNHG17 promotes gastric cancer progression by epigenetically silencing of p15 and p57. J Cell Physiol. 2019;234:5163-74.

73. Luo T, Zhao J, Lu Z, Bi J, Pang T, Cui H, Yang B, Li W, Wang Y, Wu S, Xue X. Characterization of long non-coding RNAs and MEF2C-AS1 identified as a novel biomarker in diffuse gastric cancer. Transl Oncol. 2018;11:1080-9.

74. Tan L, Yang Y, Shao Y, Zhang H, Guo J. Plasma IncRNA-GACAT2 is a valuable marker for the screening of gastric cancer. Oncol Lett. 2016;12:4845-9.

75. Gao J, Cao R, Mu H. Long non-coding RNA UCA1 may be a novel diagnostic and predictive biomarker in plasma for early gastric cancer. Int J Clin Exp Pathol. 2015;8:12936-42.

76. Li Q, Shao Y, Zhang X, Zheng T, Miao M, Qin L, Wang B, Ye G, Xiao B, Guo J. Plasma long noncoding RNA protected by exosomes as a potential stable biomarker for gastric cancer. Tumour Biol. 2015;36:2007-12.

77. Xian HP, Zhuo ZL, Sun YJ, Liang B, Zhao XT. Circulating long non-coding RNAs HULC and ZNFX1-AS1 are potential biomarkers in patients with gastric cancer. Oncol Lett. 2018;16:4689-98.

78. Wang B, Chen H, Zhang Y. Involvement of GASL1 in postoperative distant recurrence of gastric adenocarcinoma after gastrectomy distal resection and the possible mechanism. J Cell Biochem. 2019;120:11454-61.

79. Peng $C, L i X, Y u Y, C$ Chen J. LncRNA GASL1 inhibits tumor growth in gastric carcinoma by inactivating the Wnt/beta-catenin signaling pathway. Exp Ther Med. 2019;17:4039-45.

80. Zhu K, Ren Q. Zhao Y: IncRNA MALAT1 overexpression promotes proliferation, migration and invasion of gastric cancer by activating the PI3KJAKT pathway. Oncol Lett. 2019;17:5335-42.

81. Xia H, Chen Q, Chen Y, Ge X, Leng W, Tang Q, Ren M, Chen L, Yuan D, Zhang Y, et al. The IncRNA MALAT1 is a novel biomarker for gastric cancer metastasis. Oncotarget. 2016;7:56209-18.

82. Jin C, Shi W, Wang F, Shen X, Qi J, Cong H, Yuan J, Shi L, Zhu B, Luo X, et al. Long non-coding RNA HULC as a novel serum biomarker for diagnosis and prognosis prediction of gastric cancer. Oncotarget. 2016;7:51763-72.

83. Arita T, Ichikawa D, Konishi H, Komatsu S, Shiozaki A, Shoda K, Kawaguchi T, Hirajima S, Nagata H, Kubota T, et al. Circulating long non-coding RNAs in plasma of patients with gastric cancer. Anticancer Res. 2013;33:3185-93.

84. Zhou X, Yin C, Dang Y, Ye F, Zhang G. Identification of the long non-coding RNA H19 in plasma as a novel biomarker for diagnosis of gastric cancer. Sci Rep. 2015;5:11516.

85. Mohamed WA, Schaalan MF, Ramadan B. The expression profiling of circulating miR-204, miR-182, and IncRNA H19 as novel potential biomarkers for the progression of peptic ulcer to gastric cancer. J Cell Biochem. 2019; 120:13464-77.

86. Yoruker EE, Keskin M, Kulle CB, Holdenrieder S, Gezer U. Diagnostic and prognostic value of circulating IncRNA H19 in gastric cancer. Biomed Rep. 2018:9:181-6.

87. Feng W, Zong W, Li Y, Shen X, Cui X, Ju S. Abnormally expressed long noncoding RNA B3GALT5-AS1 may serve AS a biomarker for the diagnostic and prognostic of gastric cancer. J Cell Biochem. 2020;121:557-65.

88. Liu Y, Zhang YM, Ma FB, Pan SR, Liu BZ. Long noncoding RNA HOXA11-AS promotes gastric cancer cell proliferation and invasion via SRSF1 and functions as a biomarker in gastric cancer. World J Gastroenterol. 2019;25: 2763-75.

89. Li Y, Li D, Zhao M, Huang S, Zhang Q, Lin H, Wang W, Li K, Li Z, Huang W, et al. Long noncoding RNA SNHG6 regulates p21 expression via activation of the JNK pathway and regulation of EZH2 in gastric cancer cells. Life Sci. 2018:208:295-304

90. Pan L, Liang W, Gu J, Zang X, Huang Z, Shi H, Chen J, Fu M, Zhang P, Xiao $X$, et al. Long noncoding RNA DANCR is activated by SALL4 and promotes the proliferation and invasion of gastric cancer cells. Oncotarget. 2018;9: 1915-30.

91. Fu M, Huang Z, Zang X, Pan L, Liang W, Chen J, Qian H, Xu W, Jiang P, Zhang X. Long noncoding RNA LINC00978 promotes cancer growth and acts as a diagnostic biomarker in gastric cancer. Cell Prolif. 2018;51:e12425.

92. Zhou H, Wang F, Chen H, Tan Q, Qiu S, Chen S, Jing W, Yu M, Liang C, Ye S, Tu J. Increased expression of long-noncoding RNA ZFAS1 is associated with epithelial-mesenchymal transition of gastric cancer. Aging (Albany NY). 2016;8:2023-38.

93. Pan L, Liang W, Fu M, Huang ZH, Li X, Zhang W, Zhang P, Qian H, Jiang PC, Xu WR, Zhang X. Exosomes-mediated transfer of long noncoding RNA
ZFAS1 promotes gastric cancer progression. J Cancer Res Clin Oncol. 2017; 143:991-1004.

94. Cai C, Zhang H, Zhu Y, Zheng P, Xu Y, Sun J, Zhang M, Lan T, Gu B, Li S, Ma P. Serum Exosomal long noncoding RNA pcsk2-2:1 as a potential novel diagnostic biomarker for gastric Cancer. Onco Targets Ther. 2019;12:10035-41.

95. Li S, Zhang M, Zhang H, Hu K, Cai C, Wang J, Shi L, Ma P, Xu Y, Zheng P. Exosomal long noncoding RNA Inc-GNAQ-6:1 may serve as a diagnostic marker for gastric cancer. Clin Chim Acta. 2020;501:252-7.

96. Xu H, Zhou J, Tang J, Min X, Yi T, Zhao J, Ren Y. Identification of serum exosomal IncRNA MIAT as a novel diagnostic and prognostic biomarker for gastric cancer. J Clin Lab Anal. 2020:e23323..

97. Yang Z, Sun Y, Liu R, Shi Y, Ding S. Plasma long noncoding RNAs PANDAR, FOXD2-AS1, and SMARCC2 AS potential novel diagnostic biomarkers for gastric cancer. Cancer Manag Res. 2019;11:6175-84.

98. Ghaedi H, Mozaffari MAN, Salehi Z, Ghasemi H, Zadian SS, Alipoor S, Hadianpour S, Alipoor B. Co-expression profiling of plasma miRNAs and long noncoding RNAs in gastric cancer patients. Gene. 2019;687:135-42.

99. Liu J, Wang J, Song Y, Ma B, Luo J, Ni Z, Gao P, Sun J, Zhao J, Chen X, Wang $Z$. A panel consisting of three novel circulating IncRNAs, is it a predictive tool for gastric cancer? J Cell Mol Med. 2018;22:3605-13.

100. Ke D, Li H, Zhang Y, An Y, Fu H, Fang X, Zheng X. The combination of circulating long noncoding RNAs AK001058, INHBA-AS1, MIR4435-2HG, and CEBPA-AS1 fragments in plasma serve as diagnostic markers for gastric cancer. Oncotarget. 2017;8:21516-25.

101. Zheng R, Liang J, Lu J, Li S, Zhang G, Wang X, Liu M, Wang W, Chu H, Tao G, et al. Genome-wide long non-coding RNAs identified a panel of novel plasma biomarkers for gastric cancer diagnosis. Gastric Cancer. 2019;22:731-41.

102. Hashad D, Elbanna A, Ibrahim A, Khedr G. Evaluation of the role of circulating long non-coding RNA H19 as a promising novel biomarker in plasma of patients with gastric Cancer. J Clin Lab Anal. 2016;30:1100-5.

103. Zong W, Feng W, Jiang Y, Ju S, Cui M, Jing R. Evaluating the diagnostic and prognostic value of serum long non-coding RNA CTC-497E21.4 in gastric cancer. Clin Chem Lab Med. 2019;57:1063-72.

104. Zhao R, Zhang Y, Zhang X, Yang Y, Zheng X, Li X, Liu Y, Zhang Y. Exosomal long noncoding RNA HOTTIP as potential novel diagnostic and prognostic biomarker test for gastric cancer. Mol Cancer. 2018;17:68.

105. Tirada N, Aujero M, Khorjekar G, Richards S, Chopra J, Dromi S, loffe O. Breast Cancer tissue markers, genomic profiling, and other prognostic factors: a primer for radiologists. Radiographics. 2018;38:1902-20.

106. Dong L, Lin W, Qi P, Xu MD, Wu X, Ni S, Huang D, Weng WW, Tan C, Sheng $W$, et al. Circulating long RNAs in serum extracellular vesicles: their characterization and potential application as biomarkers for diagnosis of colorectal Cancer. Cancer Epidemiol Biomark Prev. 2016;25:1158-66.

107. Hauser P, Wang S, Didenko W. Apoptotic bodies: selective detection in extracellular vesicles. Methods Mol Biol. 2017;1554:193-200.

108. van Niel G, D'Angelo G, Raposo G. Shedding light on the cell biology of extracellular vesicles. Nat Rev Mol Cell Biol. 2018;19:213-28.

109. Fu M, Gu J, Jiang P, Qian H, Xu W, Zhang X. Exosomes in gastric cancer: roles, mechanisms, and applications. Mol Cancer. 2019:18:41.

110. Sung J, Kim N, Lee J, Hwang YJ, Kim HW, Chung JW, Kim JW, Lee DH. Associations among gastric juice pH, atrophic gastritis, intestinal metaplasia and helicobacter pylori infection. Gut Liver. 2018;12:158-64.

111. Fei ZH, Yu XJ, Zhou M, Su HF, Zheng Z, Xie CY. Upregulated expression of long non-coding RNA LINC00982 regulates cell proliferation and its clinical relevance in patients with gastric cancer. Tumour Biol. 2016;37:1983-93.

112. Shao Y, Ye M, Jiang X, Sun W, Ding X, Liu Z, Ye G, Zhang X, Xiao B, Guo J. Gastric juice long noncoding RNA used as a tumor marker for screening gastric cancer. Cancer. 2014;120:3320-8.

113. Yang Y, Shao Y, Zhu M, Li Q, Yang F, Lu X, Xu C, Xiao B, Sun Y, Guo J. Using gastric juice IncRNA-ABHD11-AS1 AS a novel type of biomarker in the screening of gastric cancer. Tumour Biol. 2016;37:1183-8.

114. Leary M, Heerboth S, Lapinska K, Sarkar S. Sensitization of drug resistant Cancer cells: a matter of combination therapy. Cancers (Basel). 2018;10:483.

115. Chakraborty S, Mir KB, Seligson ND, Nayak D, Kumar R, Goswami A. Integration of EMT and cellular survival instincts in reprogramming of programmed cell death to anastasis. Cancer Metastasis Rev. 2020.

116. Du B, Shim JS. Targeting epithelial-Mesenchymal transition (EMT) to overcome drug resistance in Cancer. Molecules. 2016;21:965.

117. Dong J, Qin Z, Zhang WD, Cheng G, Yehuda AG, Ashby CR Jr, Chen ZS, Cheng XD, Qin JJ. Medicinal chemistry strategies to discover P-glycoprotein inhibitors: An update. Drug Resist Updat. 2020;49:100681. 
118. Qin JJ, Yan L, Zhang J, Zhang WD. STAT3 as a potential therapeutic target in triple negative breast cancer: a systematic review. J Exp Clin Cancer Res. 2019;38:195

119. Qin JJ, Cheng XD, Zhang J, Zhang WD. Dual roles and therapeutic potential of Keap1-Nrf2 pathway in pancreatic cancer: a systematic review. Cell Commun Signal. 2019;17:121.

120. Zhao W, Shan B, He D, Cheng Y, Li B, Zhang C, Duan C. Recent Progress in characterizing long noncoding RNAs in Cancer drug resistance. J Cancer. 2019;10:6693-702

121. Xiao Y, Pan J, Geng Q, Wang G. LncRNA MALAT1 increases the stemness of gastric cancer cells via enhancing SOX2 mRNA stability. FEBS Open Bio. 2019;9:1212-22.

122. YiRen $H$, YingCong $Y$, Sunwu $Y$, Keqin $L$, Xiaochun $T$, Senrui $C$, Ende $C$, XiZhou L, Yanfan C. Long noncoding RNA MALAT1 regulates autophagy associated chemoresistance via miR-23b-3p sequestration in gastric cancer Mol Cancer. 2017;16:174

123. Xi Z, Si J, Nan J. LncRNA MALAT1 potentiates autophagyassociated cisplatin resistance by regulating the microRNA30b/autophagyrelated gene 5 axis in gastric cancer. Int J Oncol. 2019;54:239-48.

124. Hang Q, Sun R, Jiang C, Li Y. Notch 1 promotes cisplatin-resistant gastric cancer formation by upregulating IncRNA AK022798 expression. Anti-Cancer Drugs. 2015;26:632-40

125. Wang Z, Wang Q, Xu G, Meng N, Huang X, Jiang Z, Chen C, Zhang Y, Chen J, $\mathrm{Li} A$, et al. The long noncoding RNA CRAL reverses cisplatin resistance via the miR-505/CYLD/AKT axis in human gastric cancer cells. RNA Biol. 2020:1-14.

126. Wang S, Chen W, Yu H, Song Z, Li Q, Shen X, Wu Y, Zhu L, Ma Q. Xing D: IncRNA ROR promotes gastric Cancer drug resistance. Cancer Control. 2020; 27:1073274820904694

127. Zeng L, Liao Q, Zou Z, Wen Y, Wang J, Liu C, He Q, Weng N, Zeng J, Tang $\mathrm{H}$, et al. Long non-coding RNA XLOC_006753 promotes the development of multidrug resistance in gastric Cancer cells through the PI3K/AKT/mTOR signaling pathway. Cell Physiol Biochem. 2018;51:1221-36.

128. He W, Liang B, Wang C, Li S, Zhao Y, Huang Q, Liu Z, Yao Z, Wu Q, Liao W, et al. MSC-regulated IncRNA MACC1-AS1 promotes stemness and chemoresistance through fatty acid oxidation in gastric cancer. Oncogene. 2019;38:4637-54.

129. Zhou Z, Lin Z, He Y, Pang X, Wang Y, Ponnusamy M, Ao X, Shan P, Tariq MA, Li P, Wang J. The long noncoding RNA D63785 regulates chemotherapy sensitivity in human gastric Cancer by targeting miR-422a. Mol Ther Nucleic Acids. 2018;12:405-19.

130. Zhang C, Qian H, Liu K, Zhao W, Wang L. A feedback loop regulation of LINC01433 and YAP promotes malignant behavior in gastric Cancer cells. Onco Targets Ther. 2019;12:7949-62.

131. Ye Y, Yang S, Han Y, Sun J, Xv L, Wu L, Ming L. HOXD-AS1 confers cisplatin resistance in gastric cancer through epigenetically silencing PDCD4 via recruiting EZH2. Open Biol. 2019;9:190068.

132. Xin L, Zhou Q, Yuan YW, Zhou LQ, Liu L, Li SH, Liu C. METase/IncRNA HULC/ FoxM1 reduced cisplatin resistance in gastric cancer by suppressing autophagy. J Cancer Res Clin Oncol. 2019;145:2507-17.

133. Zhang Y, Song X, Wang X, Hu J, Jiang L. Silencing of LncRNA HULC enhances chemotherapy induced apoptosis in human gastric Cancer. J Med Biochem. 2016;35:137-43.

134. Guo Y, Yue P, Wang Y, Chen G, Li Y. PCAT-1 contributes to cisplatin resistance in gastric cancer through miR-128/ZEB1 axis. Biomed Pharmacother. 2019;118:109255.

135. Li H, Ma X, Yang D, Suo Z, Dai R, Liu C. PCAT-1 contributes to cisplatin resistance in gastric cancer through epigenetically silencing PTEN via recruiting EZH2. J Cell Biochem. 2020;121:1353-61.

136. Li Y, LV S, Ning H, Li K, Zhou X, Xv H, Wen H. Down-regulation of CASC2 contributes to cisplatin resistance in gastric cancer by sponging miR-19a. Biomed Pharmacother. 2018;108:1775-82.

137. Cheng C, Qin Y, Zhi Q, Wang J, Qin C. Knockdown of long non-coding RNA HOTAIR inhibits cisplatin resistance of gastric cancer cells through inhibiting the PI3K/Akt and Wnt/beta-catenin signaling pathways by up-regulating miR-34a. Int J Biol Macromol. 2018;107:2620-9.

138. Jia J, Zhan D, Li J, Li Z, Li H, Qian J. The contrary functions of IncRNA HOTAIR/miR-17-5p/PTEN axis and Shenqifuzheng injection on chemosensitivity of gastric cancer cells. J Cell Mol Med. 2019;23:656-69.

139. Wang H, Qin R, Guan A, Yao Y, Huang Y, Jia H, Huang W, Gao J. HOTAIR enhanced paclitaxel and doxorubicin resistance in gastric cancer cells partly through inhibiting miR-217 expression. J Cell Biochem. 2018;119:7226-34.
140. Yan J, Dang Y, Liu S, Zhang Y, Zhang G. LncRNA HOTAIR promotes cisplatin resistance in gastric cancer by targeting miR-126 to activate the PI3K/AKT/ MRP1 genes. Tumour Biol. 2016;37:16345-55.

141. Song H, Xu Y, Shi L, Xu T, Fan R, Cao M, Xu W, Song J. LncRNA THOR increases the stemness of gastric cancer cells via enhancing SOX9 mRNA stability. Biomed Pharmacother. 2018;108:338-46.

142. Wu X, Zheng Y, Han B, Dong X. Long noncoding RNA BLACAT1 modulates $A B C B 1$ to promote oxaliplatin resistance of gastric cancer via sponging miR361. Biomed Pharmacother. 2018;99:832-8.

143. Zhang X, Bo P, Liu L, Zhang X, Li J. Overexpression of long non-coding RNA GHET1 promotes the development of multidrug resistance in gastric cancer cells. Biomed Pharmacother. 2017;92:580-5.

144. Lan WG, Xu DH, Xu C, Ding CL, Ning FL, Zhou YL, Ma LB, Liu CM, Han X. Silencing of long non-coding RNA ANRIL inhibits the development of multidrug resistance in gastric cancer cells. Oncol Rep. 2016:36:263-70.

145. Shang C, Guo Y, Zhang J, Huang B. Silence of long noncoding RNA UCA1 inhibits malignant proliferation and chemotherapy resistance to adriamycin in gastric cancer. Cancer Chemother Pharmacol. 2016;77:1061-7.

146. Fang $Q$, Chen X, Zhi X. Long non-coding RNA (LncRNA) Urothelia carcinoma associated 1 (UCA1) increases multi-drug resistance of gastric Cancer via Downregulating miR-27b. Med Sci Monit. 2016;22:3506-13.

147. Du P, Hu C, Qin Y, Zhao J, Patel R, Fu Y, Zhu M, Zhang W, Huang G. LncRNA PVT1 mediates Antiapoptosis and 5-fluorouracil resistance via increasing Bcl2 expression in gastric Cancer. J Oncol. 2019;2019:9325407.

148. Zhang XW, Bu P, Liu L, Zhang XZ, Li J. Overexpression of long non-coding RNA PVT1 in gastric cancer cells promotes the development of multidrug resistance. Biochem Biophys Res Commun. 2015;462:227-32.

149. Wang Y, Zhang D, Wu K, Zhao Q, Nie Y, Fan D. Long noncoding RNA MRUL promotes ABCB1 expression in multidrug-resistant gastric cancer cell sublines. Mol Cell Biol. 2014:34:3182-93.

150. Li M, Zhang YY, Shang J, Xu YD. LncRNA SNHG5 promotes cisplatin resistance in gastric cancer via inhibiting cell apoptosis. Eur Rev Med Pharmacol Sci. 2019;23:4185-91.

151. Xu YD, Shang J, Li M, Zhang YY. LncRNA DANCR accelerates the development of multidrug resistance of gastric cancer. Eur Rev Med Pharmacol Sci. 2019;23:2794-802.

152. Zhang Y, Li Q, Yu S, Zhu C, Zhang Z, Cao H, Xu J. Long non-coding RNA FAM84B-AS promotes resistance of gastric cancer to platinum drugs through inhibition of FAM84B expression. Biochem Biophys Res Commun. 2019;509:753-62.

153. Wang L, Chunyan Q, Zhou Y, He Q, Ma Y, Ga Y, Wang X. BCAR4 increase cisplatin resistance and predicted poor survival in gastric cancer patients. Eur Rev Med Pharmacol Sci. 2017;21:4064-70.

154. Zhang J, Zhao B, Chen X, Wang Z, Xu H, Huang B. Silence of long noncoding RNA NEAT1 inhibits malignant biological behaviors and chemotherapy resistance in gastric Cancer. Pathol Oncol Res. 2018:24:109-13.

155. Han Y, Ye J, Wu D, Wu P, Chen Z, Chen J, Gao S, Huang J. LEIGC long noncoding RNA acts as a tumor suppressor in gastric carcinoma by inhibiting the epithelial-to-mesenchymal transition. BMC Cancer. 2014;14:932.

156. Shang C, Sun L, Zhang J, Zhao B, Chen X, Xu H, Huang B. Silence of cancer susceptibility candidate 9 inhibits gastric cancer and reverses chemoresistance. Oncotarget. 2017;8:15393-8.

157. Mao Z, Wu Y, Zhou J, Xing C. Salinomycin reduces epithelial-mesenchymal transition-mediated multidrug resistance by modifying long noncoding RNA HOTTIP expression in gastric cancer cells. Anti-Cancer Drugs. 2019;30: $892-9$.

158. Wu H, Liu B, Chen Z, Li G, Zhang Z. MSC-induced IncRNA HCP5 drove fatty acid oxidation through miR-3619-5p/AMPK/PGC1alpha/CEBPB axis to promote stemness and chemo-resistance of gastric cancer. Cell Death Dis. 2020;11:233.

159. Wang W, Qin JJ, Voruganti S, Nijampatnam B, Velu SE, Ruan KH, Hu M, Zhou J, Zhang R. Discovery and characterization of dual inhibitors of MDM2 and NFAT1 for pancreatic Cancer therapy. Cancer Res. 2018;78:5656-67.

160. Wang W, Yang J, Liao YY, Cheng G, Chen J, Cheng XD, Qin JJ, Shao Z. Cytotoxic Nitrogenated Azaphilones from the Deep-Sea-derived fungus Chaetomium globosum MP4-S01-7. J Nat Prod. 2020;83:1157-66.

161. Mohammad RM, Muqbil I, Lowe L, Yedjou C, Hsu HY, Lin LT, Siegelin MD, Fimognari C, Kumar NB, Dou QP, et al. Broad targeting of resistance to apoptosis in cancer. Semin Cancer Biol. 2015;35(Suppl):S78-s103.

162. D'Arcy MS. Cell death: a review of the major forms of apoptosis, necrosis and autophagy. Cell Biol Int. 2019;43:582-92. 
163. Pfeffer CM, Singh ATK. Apoptosis: a target for anticancer therapy. Int J Mol Sci. 2018;19:448

164. Cavalcante GC, Schaan AP, Cabral GF, Santana-da-Silva MN, Pinto P, Vidal AF, Ribeiro-Dos-Santos A. A Cell's fate: An overview of the molecular biology and genetics of apoptosis. Int J Mol Sci. 2019;20:4133.

165. Fianco G, Contadini C, Ferri A, Cirotti C, Stagni V, Barila D. Caspase-8: a novel target to overcome resistance to chemotherapy in Glioblastoma. Int J Mol Sci. 2018;19:3798.

166. Garcia-Aranda M, Perez-Ruiz E, Redondo M. Bcl-2 inhibition to overcome resistance to chemo- and immunotherapy. Int J Mol Sci. 2018;19:3950.

167. Binju M, Amaya-Padilla MA, Wan G, Gunosewoyo H, Suryo Rahmanto Y, Yu $Y$. Therapeutic inducers of apoptosis in ovarian Cancer. Cancers (Basel). 2019;11:1786

168. Verret B, Cortes J, Bachelot T, Andre F, Arnedos M. Efficacy of PI3K inhibitors in advanced breast cancer. Ann Oncol. 2019;30:X12-20.

169. Lin KN, Jiang YL, Zhang SG, Huang SY, Li H. Grape seed proanthocyanidin extract reverses multidrug resistance in HL-60/ADR cells via inhibition of the PI3K/Akt signaling pathway. Biomed Pharmacother. 2020;125:109885.

170. Nguyen CDK, Yi C. YAP/TAZ signaling and resistance to Cancer therapy. Trends Cancer. 2019;5:283-96.

171. Ye C, Wang W, Xia G, Yu C, Yi Y, Hua C, Tu F, Shen L, Chen C, Sun W, Zheng Z. A novel curcumin derivative CL-6 exerts antitumor effect in human gastric cancer cells by inducing apoptosis through hippo-YAP signaling pathway. Onco Targets Ther. 2019;12:2259-69.

172. Yang $X M$, Cao $X Y$, He $P$, Li J, Feng MX, Zhang $Y L$, Zhang $X L$, Wang $Y H$, Yang $Q$, Zhu $L$, et al. Overexpression of rac GTPase activating protein 1 contributes to proliferation of cancer cells by reducing hippo signaling to promote cytokinesis. Gastroenterology. 2018;155:1233-1249.e1222.

173. Chiarini F, Paganelli F, Martelli AM, Evangelisti C. The role played by Wnt/ beta-catenin signaling pathway in acute lymphoblastic leukemia. Int J Mol Sci. 2020;21:1098.

174. Roy S, Kar M, Roy S, Padhi S, Kumar A, Thakur S, Akhter Y, Gatto G, Banerjee B. Inhibition of CD44 sensitizes cisplatin-resistance and affects Wnt/betacatenin signaling in HNSCC cells. Int J Biol Macromol. 2020;149:501-12.

175. Ram Makena M, Gatla H, Verlekar D, Sukhavasi S. M KP, K CP: Wnt/betacatenin signaling: the culprit in pancreatic carcinogenesis and therapeutic resistance. Int J Mol Sci. 2019;20:4242.

176. Harb J, Lin PJ, Hao J. Recent development of Wnt signaling pathway inhibitors for Cancer therapeutics. Curr Oncol Rep. 2019;21:12.

177. Yin J, Ni B, Liao WG, Gao YQ. Hypoxia-induced apoptosis of mouse spermatocytes is mediated by HIF-1alpha through a death receptor pathway and a mitochondrial pathway. J Cell Physiol. 2018;233:1146-55.

178. Mendez-Blanco C, Fondevila F, Fernandez-Palanca P, Garcia-Palomo A, Pelt JV, Verslype C, Gonzalez-Gallego J, Mauriz JL. Stabilization of hypoxiainducible factors and BNIP3 promoter methylation contribute to acquired Sorafenib resistance in human Hepatocarcinoma cells. Cancers (Basel). 2019; 11:1984.

179. Ge X, Pan MH, Wang L, Li W, Jiang C, He J, Abouzid K, Liu LZ, Shi Z, Jiang $\mathrm{BH}$. Hypoxia-mediated mitochondria apoptosis inhibition induces temozolomide treatment resistance through miR-26a/bad/Bax axis. Cell Death Dis. 2018;9:1128.

180. Lu W, Kang Y. Epithelial-Mesenchymal plasticity in Cancer progression and metastasis. Dev Cell. 2019:49:361-74.

181. Olteanu GE, Mihai IM, Bojin F, Gavriliuc O, Paunescu V. The natural adaptive evolution of cancer: the metastatic ability of cancer cells. Bosn J Basic Med Sci. 2020.

182. Teeuwssen M, Fodde R. Wnt signaling in ovarian Cancer Stemness, EMT, and therapy resistance. J Clin Med. 2019;8:1658.

183. Liu B, Wu S, Ma J, Yan S, Xiao Z, Wan L, Zhang F, Shang M. Mao a: IncRNA GAS5 reverses EMT and tumor stem cell-mediated gemcitabine resistance and metastasis by targeting miR-221/SOCS3 in pancreatic Cancer. Mol Ther Nucleic Acids. 2018;13:472-82.

184. Dong H, Hu J, Zou K, Ye M, Chen Y, Wu C, Chen X, Han M. Activation of LnCRNA TINCR by H3K27 acetylation promotes Trastuzumab resistance and epithelial-mesenchymal transition by targeting MicroRNA-125b in breast Cancer. Mol Cancer. 2019;18:3.

185. Yadav AK, Desai NS. Cancer stem cells: acquisition, characteristics, therapeutic implications, targeting strategies and future prospects. Stem Cell Rev Rep. 2019;15:331-55.

186. Lathia J, Liu H, Matei D. The clinical impact of Cancer stem cells. Oncologist. 2020;25:123-31.
187. Najafi M, Farhood B, Mortezaee K. Cancer stem cells (CSCs) in cancer progression and therapy. J Cell Physiol. 2019;234:8381-95.

188. Prasad S, Ramachandran S, Gupta N, Kaushik I, Srivastava SK. Cancer cells stemness: a doorstep to targeted therapy. Biochim Biophys Acta Mol basis Dis. 1866;2020:165424

189. Wang J, Quan Y, LV J, Gong S, Dong D. BRD4 promotes glioma cell stemness via enhancing miR-142-5p-mediated activation of Wnt/betacatenin signaling. Environ Toxicol. 2020;35:368-76.

190. Liu Q, Sun J, Luo Q, Ju Y, Song G. Salinomycin suppresses tumorigenicity of liver cancer stem cells and Wnt/beta-catenin signaling. Curr Stem Cell Res Ther. 2020.

191. Allen EA, Baehrecke EH. Autophagy in animal development. Cell Death Differ. 2020;27:903-18.

192. Levy JMM, Towers CG, Thorburn A. Targeting autophagy in cancer. Nat Rev Cancer. 2017:17:528-42.

193. Li X, He S, Ma B. Autophagy and autophagy-related proteins in cancer. Mol Cancer. 2020;19:12.

194. Yang Y, Klionsky DJ. Autophagy and disease: unanswered questions. Cell Death Differ. 2020;27:858-71.

195. Ho CJ, Gorski SM. Molecular mechanisms underlying autophagy-mediated treatment resistance in Cancer. Cancers (Basel). 2019;11:1775.

196. Li YJ, Lei YH, Yao N, Wang CR, Hu N, Ye WC, Zhang DM, Chen ZS. Autophagy and multidrug resistance in cancer. Chin J Cancer. 2017;36:52.

197. Robey RW, Pluchino KM, Hall MD, Fojo AT, Bates SE, Gottesman MM. Revisiting the role of $A B C$ transporters in multidrug-resistant cancer. Nat Rev Cancer. 2018;18:452-64.

198. Amawi H, Sim HM, Tiwari AK, Ambudkar SV, Shukla S. ABC transportermediated multidrug-resistant Cancer. Adv Exp Med Biol. 2019;1141:549-80.

199. Hu Q, Baeg GH. Role of epigenome in tumorigenesis and drug resistance. Food Chem Toxicol. 2017;109:663-8.

200. Xu W, Zhou B, Zhao X, Zhu L, Xu J, Jiang Z, Chen D, Wei Q, Han M, Feng L, et al. KDM5B demethylates $\mathrm{H} 3 \mathrm{~K} 4$ to recruit $\mathrm{XRCC} 1$ and promote chemoresistance. Int J Biol Sci. 2018:14:1122-32.

201. Schizas D, Mastoraki A, Naar L, Tsilimigras DI, Katsaros I, Fragkiadaki V, Karachaliou GS, Arkadopoulos N, Liakakos T, Moris D. Histone Deacetylases (HDACs) in gastric cancer: An update of their emerging prognostic and therapeutic role. Curr Med Chem. 2019.

202. Arun G, Diermeier SD, Spector DL. Therapeutic targeting of long noncoding RNAs in Cancer. Trends Mol Med. 2018;24:257-77.

\section{Publisher's Note}

Springer Nature remains neutral with regard to jurisdictional claims in published maps and institutional affiliations.

Ready to submit your research? Choose BMC and benefit from:

- fast, convenient online submission

- thorough peer review by experienced researchers in your field

- rapid publication on acceptance

- support for research data, including large and complex data types

- gold Open Access which fosters wider collaboration and increased citations

- maximum visibility for your research: over $100 \mathrm{M}$ website views per year

At BMC, research is always in progress.

Learn more biomedcentral.com/submissions 